June 1999

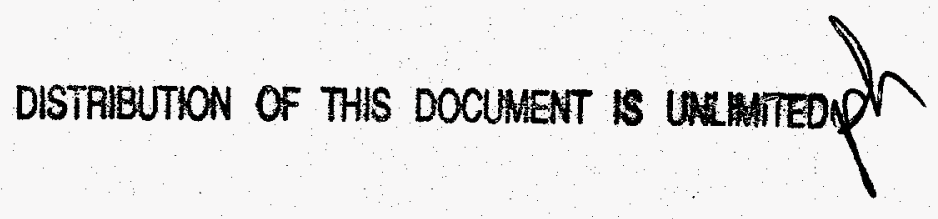

\begin{abstract}
NOTICE
This report was prepared as an account of work sponsored by the United States Government. Neither the United States, nor the United States Department of Energy, nor any of their employees, nor any of their contractors, subcontractors, or their employees, makes any warranty, express or implied, or assumes any legal liability or responsibility for the accuracy, completeness or usefulness of any information, apparatus, product or process disclosed, or represents that its use would not infringe privately owned rights.
\end{abstract}




\section{DISCLAIMER}

This report was prepared as an account of work sponsored by an agency of the United States Government. Neither the United States Government nor any agency thereof, nor any of their employees, make any warranty, express or implied, or assumes any legal liability or responsibility for the accuracy, completeness, or usefulness of any information, apparatus, product, or process disclosed, or represents that its use would not infringe privately owned rights. Reference herein to any specific commercial product, process, or service by trade name, trademark, manufacturer, or otherwise does not necessarily constitute or imply its endorsement, recommendation, or favoring by the United States Government or any agency thereof. The views and opinions of authors expressed herein do not necessarily state or reflect those of the United States Government or any agency thereof. 


\section{DISCLAIMER}

Portions of this document may be illegible in electronic image products. Images are produced from the best available original document. 


\title{
Instrumentation Development for Multi-Dimensional Two-Phase Flow Modeling
}

\author{
G.J. Kirouac, T.A. Trabold, P.F. Vassallo, W.E. Moore and R. Kumar
}

\author{
Lockheed Martin Corporation \\ P.O. Box 1072 \\ Schenectady, New York 12301
}

\begin{abstract}
A multi-faceted instrumentation approach is described which has played a significant role in obtaining fundamental data for two-phase flow model development. This experimental work supports the development of a three-dimensional, two-fluid, four field computational analysis capability. The goal of this development is to utilize mechanistic models and fundamental understanding rather than rely on empirical correlations to describe the interactions in two-phase flows. The four fields (two dispersed and two continuous) provide a means for predicting the flow topology and the local variables over the full range of flow regimes. The fidelity of the model development can be verified by comparisons of the three-dimensional predictions with local measurements of the flow variables. Both invasive and non-invasive instrumentation techniques and their strengths and limitations are discussed. A critical aspect of this instrumentation development has been the use of a low pressure/temperature modeling fluid (R-134a) in a vertical duct which permits full optical access to visualize the flow fields in all two-phase flow regimes. The modeling fluid accurately simulates boiling steam-water systems. Particular attention is focused on the use of a gamma densitometer to obtain line-averaged and cross-sectional averaged void fractions. Hot-film anemometer probes provide data on local void fraction, interfacial frequency, bubble and droplet size, as well as information on the behavior of the liquid-vapor interface in annular flows. A laser Doppler velocimeter is used to measure the velocity of liquidvapor interfaces in bubbly, slug and annular flows. Flow visualization techniques are also used to obtain a qualitative understanding of the two-phase flow structure, and to obtain supporting quantitative data on bubble size. Examples of data obtained with these various measurement methods are shown.
\end{abstract}




\section{Nomenclature}

A

$d$

$d_{s}$

$D_{h}$

E

$f$

$g$

I

$I_{O}$

$L$

N

$P$

$Q$

$t$

$T_{\text {in }}$

$U$

$u^{\prime}$

$V$

$V_{T}$

$w$

W

$X$

$Y$

Z

Greek symbols

$\alpha$

$\rho$

$\Delta p$

$\sigma$

$\tau_{m}$

$\mu \mathrm{t}$

Subscripts

$b$

cl

cv

$d$

$d l$

$d v$

$i$

g

l

$2 \phi$ area

diameter

hot-film anemometer (HFA) probe sensor spacing

test section hydraulic diameter

cross-correlation function

interfacial frequency

gravitational acceleration

gamma densitometer system (GDS) count rate in two-phase flow GDS calibration constant with empty test section .

test section length

number of samples in laser Doppler velocimeter (LDV) velocity

measurement

test section absolute pressure

net wall heat input

time; test section thickness dimension

liquid inlet temperature

mean LDV velocity

LDV root-mean-square velocity fluctuation

velocity; HFA output voltage

threshold voltage for HFA void fraction calculation

mass flow rate

test section width

streamwise position

transverse position

spacing position

void fraction

density

difference between liquid and vapor densities

surface tension

most probable time for interfacial transport between HFA sensors

GDS calibration constant with subcooled liquid-filled test section 


\section{Introduction}

The development of computational models to predict two-phase flow behavior relies on physical understanding of complex interactions that occur at the interfaces between the liquid and the gas phases. To gain insight into the physical processes, and to develop multi-dimensional models of such phenomena, critical observations of the flow for various combinations of the liquid and vapor fluxes need to be made. In addition, an experimental database based on local measurements in the three-dimensional space is required to assess a code's predictive capability. Most of the experiments reported in the literature have been conducted using high liquid-to-gas density ratio adiabatic systems such as air-water at atmospheric conditions. There are few fundamental data available for steam-water systems or for modeling fluids which simulate low liquid-to-gas density ratio boiling systems. The present work was undertaken to develop and apply instrumentation suitable for use in obtaining fundamental data in a modeling fluid (nonchlorinated refrigerant $\mathrm{R}-134 \mathrm{a}^{1}$ ) which simulates boiling, pressurized water systems.

This experimental program uses various instrumentation techniques to support the development of a three-dimensional, two-fluid, four-field analysis code. Because each phase can exist either in a continuous or a dispersed field (e.g., vapor exists either as a continuous core or as bubbles), there is a need to model the two continuous and two dispersed fields. Hence, volume fractions and their spatial distributions need to be measured for all four fields. In addition, models need to be developed to describe interactions across three types of interfaces: continuous liquid and dispersed vapor (cl-dv), continuous vapor and dispersed liquid (cv-dl), and continuous liquid and continuous vapor ( $\mathrm{cl}-\mathrm{cv}$ ). Using this approach, the code can capture the physics needed to describe a subcooled liquid flowing through a duct with heated walls, undergoing nucleate boiling and progressing through a series of flow regime transitions from bubbly to annular flow. To develop models to accurately predict the local conditions and the flow topology, various experimental techniques have been applied to measure the local and averaged void fractions, and to visualize vapor-liquid interfaces and measure their velocities. Sample spatial distributions of the measured flow variables are provided in this paper with discussion as to how these support two-fluid modeling. Table 1 provides an overview of the parameters that are needed for model

1. 1,1,1,2-tetraflouroethane 
development and the models that these measurements support.

The ability to see the relevant features of the complex two-phase flow fields in all flow regimes was a key feature in the refrigerant fluid experimental system design. Hence, a long vertical, rectangular duct cross-section with fused silica windows for both the front and back faces was chosen. This permits extensive use of high speed photography and a variety of non-intrusive optical and laser techniques. In addition, the dielectric, low boiling point modeling fluid has a very low surface tension which makes use of hot-film anemometer (HFA) probes especially appropriate. Miniature HFA probes, together with a high accuracy gamma densitometer, multiple local pressure drop measurements and a laser Doppler velocimeter, are the primary instruments applied in the present work. Dual-sensor HFA probes were developed to provide point measurements of the void fraction, interfacial velocity, dispersed phase frequency and size. The gamma densitometer system has been designed to yield line- and cross-section averaged void fractions for both steady state and transient experiments. Finally, the laser Doppler system gives local velocities of both dispersed and continuous phases. Results from these three instruments can often be cross compared, giving added confidence to each measurement technique. In addition, high speed flow visualization and digital image analysis give key information on the flow topology, void size and shape, and interfacial area density.

\section{Experimental System}

The present measurements were performed in a flowing test facility which uses R-134a as a modeling fluid to simulate high pressure/temperature, boiling steam-water two-phase flows. The facility has flow capability up to about $2500 \mathrm{~kg} / \mathrm{hr}$, and operating pressure and temperature ranges up to about $2.4 \mathrm{MPa}$ and $80^{\circ} \mathrm{C}$, respectively. These conditions scale to equivalent steam-water conditions of $14 \mathrm{MPa}$ and $330^{\circ} \mathrm{C}$ when the density ratio of the vapor to liquid phase is matched. Loop flow conditions are set and controlled by programmed logic controllers, and the loop and test section data are recorded by a digital data acquisition system.

\section{Test Section}

The test section, illustrated schematically in Figure 1, is a $1.22 \mathrm{~m}$ long rectangular flow duct 
which provides full optical access to the flow field. Eight fused silica windows, $3.8 \mathrm{~cm}$ thick by $7.6 \mathrm{~cm}$ width by $27.9 \mathrm{~cm}$ length are mounted in pairs, four on each side of the test section. The test section is designed to allow sufficient length for flow to develop from subcooled single-phase flow at the inlet to annular flow at the exit. The test section has a hydraulic diameter of $4.85 \mathrm{~mm}$, width ( $Y$ dimension) of $57.2 \mathrm{~mm}$, and an aspect ratio of 22.5. The total length of the test section is approximately 250 times the hydraulic diameter. Test section heating is provided by transparent, conductive Indium-Tin-Oxide vacuum-deposited on the inside surface of each window. The heated area on each of the eight windows is $143 \mathrm{~cm}^{2}$ and is capable of supplying up to $3 \mathrm{~kW}$ of heat to the working fluid. An instrument scanning mechanism positions the gamma densitometer and other instrumentation about the test section at any vertical, streamwise location and permits scans in a horizontal plane transverse to the test section. In order to scan void distributions in both transverse directions, the gamma densitometer can be rotated $90^{\circ}$ about the test section vertical axis. Both laser and gamma beam alignment tests have shown that the positioning accuracy is about $\pm 0.025 \mathrm{~mm}$.

\section{Gamma Densitometer System (GDS)}

The gamma densitometer consists of a shielded 9 Curie Cesium -137 source located on one side of the test section and a $5.1 \mathrm{~cm}$ square Sodium Iodide ( $\mathrm{NaI}$ ) gamma detector on the opposite side. A dual slit, rotating. Tungsten collimator is incorporated into the source cask to permit two choices for the spatial resolution of the emergent gamma beams. The gamma detector module contains lead shielding for the NaI crystal, an oven and magnetic shielding for the photomultiplier, and a Tungsten collimator. The NaI detector gain is controlled by a programmed high voltage supply. The detected gamma pulses are processed through a preamp, a fast linear gate, and into a pulse-height Multi-Channel Analyzer (MCA). These nuclear electronics include a very fast "front end" analog signal processor which is the key to eliminating errors due to pulse

pileup at these extremely high counting rates. This unit prescales the counts and passes one pulse to the MCA for every 32 pulses received. The MCA accumulates a very clean gamma ray spectrum with minimal Compton scattering; therefore, integration over the full-energy-loss peak provides a gamma count that is insensitive to drift in the instrument gain. Gain drift effects are effectively eliminated by automatic feedback control of the detector high voltage; this design feature is based on computer analysis of the peak centroid position in the gamma spectrum. 
The gamma densitometer provides a direct measurement of the density of the two-phase mixture in the path of the gamma beam through the relationship:

$$
\rho_{2 \phi}=\frac{\ln \left(\frac{I_{O}}{I}\right)}{\mu t}
$$

where $I_{o}$ and $\mu$ t are calibration constants obtained from gamma count measurements at each desired measurement position, with an empty test section and a subcooled liquid-filled test section, respectively. $I$ is the count rate measured for the two-phase test condition. The two-phase density is related to the void fraction and vapor and liquid densities through the relationship:

$$
\rho_{2 \phi}=(1-\alpha) \rho_{l}+\alpha \rho_{g}
$$

where $\alpha$ is the void fraction, $\rho_{1}$ is the density of the liquid phase, and $\rho_{g}$ is the density of the vapor phase. Solving for $\alpha$ yields:

$$
\alpha=\frac{\rho_{l}-\rho_{2 \phi}}{\rho_{l}-\rho_{g}}
$$

The liquid and vapor phase densities are determined from a database of R-134a saturation properties at the measured test section exit temperature.

The gamma beam width can be changed to narrow or wide by rotating the source collimator with a remote selector switch. The gamma beam height is $19 \mathrm{~mm}$ for both of the source collimator positions. The wide beam, when directed through the edge of the test section (wide beam edge measurement), interrogates the entire cross-sectional area of the fluid and, hence, yields a measurement of the cross-sectional average void fraction. Void fraction profiles across the spacing dimension are obtained using the narrow beam directed through the test section edge (narrow beam edge scan). The effective gamma beam width (full width at half max, FWHM) at the test section for a narrow beam edge scan is $0.43 \mathrm{~mm}$. For the $0.25 \mathrm{~mm}$ steps used, each measurement location overlaps the adjacent one by about $0.18 \mathrm{~mm}$, and the fluid is interrogated to within 0.15 $\mathrm{mm}$ of the heated test section walls.

Two minute counting times were used for both wide beam and narrow beam edge measurements. The total uncertainty, based on root-sum-square combination of precision 
(random) and systematic (bias) components at $95 \%$ confidence $( \pm 2 \sigma)$, was determined for each type of GDS measurement. Each wide beam edge measurement was obtained twice and averaged, for a total uncertainty of \pm 0.017 in void fraction. For each narrow beam edge measurement, the total uncertainty is \pm 0.032 . The third type of gamma densitometer measurement is the wide beam face measurement through the thickness dimension of the test section. For this measurement, the effective gamma beam width at the test section is $4.2 \mathrm{~mm}$. These measurements ( 3 minute count) were each obtained three times and averaged. The total uncertainty for the wide beam face measurements is \pm 0.108 in void fraction. The primary limitations on the GDS measurements relate to the spatial resolution and the counting time required. In particular, accurate measurements of void fraction cannot be made much closer than $0.25 \mathrm{~mm}$ from the wall.

\section{Hot-Film Anemometer (HFA)}

To obtain local point-measurements of the void fraction, a constant temperature hot-film anemometer (HFA) was used. The HFA probe consists of a sensitive element suspended across two needles. When fluid passes the probe, this sensor is cooled, resulting in a decrease in its resistance. A fast response bridge circuit senses this loss of resistance and applies added current to maintain a constant sensor temperature. An analog-to-digital converter produces a digital record of the bridge voltage signal which is analyzed to provide a measurement of the local void fraction. The use of thermal anemometry for local measurements in chlorinated (R-113 and R-114) and nonchlorinated (R-134a and FC-72) two-phase flow refrigerant fluids has been reported previously (e.g., Dix [1]; Shiralkar and Lahey [2]; Hasan et al. [3]; Carvalho and Bergles [4]; Trabold et al. [5]).

For the present test program, dual-sensor probes were installed for local void fraction and velocity measurements along two spacing $(Z)$ and two transverse $(Y)$ dimension scans. These HFA probes consist of two active sensing elements which are separated in the streamwise (X) direction by a known distance, $\mathrm{d}_{\mathrm{s}}$. The sensing elements are platinum-coated quartz fibers with a diameter of $25.4 \mu \mathrm{m}$ and active length of $254 \mu \mathrm{m}$. A pin on the HFA probe bent $90^{\circ}$ downstream provided a means of accurately positioning the sensor by contacting the transparent heater strip attached to the opposing window. The overheat ratio (i.e., ratio of the sensor resistance during operation to resistance at the ambient temperature) was fixed at 1.09. This value is consistent with 
other reported HFA measurements in two-phase flow.

A number of signal analysis techniques for void fraction calculation have been proposed. For previous measurements in R-114 (Trabold et al. [5]), level (amplitude) thresholding was used since the fall and rise times in the output signal were so short (generally in the range 30 to 70 $\mu \mathrm{sec})$ that a nearly square wave response was observed for the passing bubbles. A threshold voltage $\left(V_{T}\right)$ was established such that for $V>V_{T}$, the active element of the HFA probe was considered to be in contact with the liquid phase. Conversely, for $V \leq V_{T}$, the probe was in contact with the vapor phase. The number of discrete voltages for which $\mathrm{V} \leq \mathrm{V}_{\mathrm{T}}$ divided by the total number of samples in a given measurement period represented the residence time fraction of the vapor phase, which is directly analogous to the local void fraction (Jones and Zuber [6]).

The general form of the HFA voltage signal in dispersed vapor flow can be explained by refering to the mechanics of a bubble interacting with the active probe element, as shown in Figure $2 \mathrm{a}$. For the hot-film to penetrate either the front or rear vapor-liquid interface, surface tension must be overcome. After penetrating the front interface, the thin liquid layer remaining on the sensor is slowly boiled off; re-wetting occurs quickly at the rear interface. The presence of smaller bubbles makes the liquid-vapor interfaces more difficult to penetrate, which also leads to relatively long rise and fall times.

In order to account for the rise and fall times in the voltage trace, the signal analysis method of Carvalho and Bergles [4] was used in which phase changes were identified by level thresholding, and slope thresholding was used to account for the void volume passage time. For experiments conducted in pool boiling of FC-72, these authors analyzed the signals by first setting a threshold voltage $\left(V_{T}\right)$ whereby for $V \leq V_{T}$ the probe was considered to be in contact with vapor.

Additionally, they proposed including voltage samples on either side of the negative bubble pulses until the slope changed sign. Once the raw voltage signal was converted into the phase indicator function (i.e., 0 for liquid, -1 for vapor), the number of voltage samples for which the vapor phase was present at the probe divided by the total number of voltage samples gave a measurement of the local ensemble-averaged vapor volume fraction. Additionally, the number of negative pulses in the phase indicator function per unit time provides a measurement of the bubble frequency, 
which enters into calculation of the mean bubble size and interfacial area concentration.

The most important part of the analysis procedure for void fraction calculation is the proper selection of the threshold voltage, $\mathrm{V}_{\mathrm{T}}$. For a given set of flow and pressure conditions, the optimum $\mathrm{V}_{\mathrm{T}}$ may be determined by plotting the voltage sample histogram, a typical example of which is shown in Figure $2 \mathrm{~b}$. The most probable vapor and liquid voltages are represented by the left and right peaks, respectively. As recommended by Trabold et al. [7], $\mathrm{V}_{\mathrm{T}}$ is selected as the voltage at the midpoint between these two peaks. The computed void fraction is only weakly dependent on $\mathrm{V}_{\mathrm{T}}$ in the range of voltages between the peaks in the voltage sample histogram.

The use of two hot-film sensors permits acquisition of interfacial velocity measurements based on the cross-correlation between the two bridge output voltage signals:

$$
E(\tau)=\lim _{T \rightarrow \infty} \frac{1}{T} \int_{0}^{T} V_{1}(t) V_{2}(t+\tau) d t
$$

The peak in the $E(\tau)$ versus time plot corresponds to the most probable time required for a gasliquid interface to travel between the HFA sensors, $\tau_{\mathrm{m}}$, from which the mean interfacial velocity may be calculated by

$$
V_{i}=\frac{d_{s}}{\tau_{m}}
$$

where $d_{s}$ is the spacing between upstream and downstream HFA sensors (typically $2 \mathrm{~mm}$ ).

The most significant limitation on HFA void fraction measurements is the need to produce an output voltage signal which has a high signal-to-noise ratio (SNR). This proves to be most difficult at high mass flux, high pressure conditions where the convective heat transfer from the HFA sensor becomes significant. For these flows, the delineation between liquid and vapor parts of the voltage signal is not clear, thereby making selection of an appropriate threshold voltage difficult. For velocity, a similar limitation does not exist, as available time-domain analysis equipment can readily formulate the cross-correlation function from signals with very low SNR. Interfacial velocity measurements were successfully obtained under all operating conditions in the current test program. 
The uncertainty bands on HFA measurements have been established based on the root-sum-square model for $95 \%$ confidence $( \pm 2 \sigma)$. The precision (random uncertainty) was calculated for both void fraction and velocity from the pooled standard deviation of repeat measurements acquired at various test conditions. Biases (systematic uncertainty) were estimated through consideration of threshold voltage selection, bubble or droplet residence time, positioning, and sampling time. For velocity, an additional source of uncertainty was associated with use of the cross-correlation for determination of the mean transport time between the sensors. Combining all these sources of uncertainty resulted in total uncertainties of \pm 0.027 in void fraction, and up to $\pm 7 \%$ on local interfacial velocity. The latter is somewhat higher near the duct walls where large velocity gradients are encountered.

\section{Laser Doppler Velocimeter.}

Laser Doppler Velocimetry is a well developed, non-intrusive technique widely used to measure velocity in single-phase flows. Its use in two-phase flow has been rather limited because of the difficulty in obtaining clean signals from an environment containing many sizes and shapes of light scattering interfaces. However, unlike the HFA probe which can only be moved perpendicular to the test section walls, LDV has the advantage of potentially being able to make velocity measurements at any point in the flow. In the application of this technique to two-phase flows, a pair of laser beams are aligned and focused to a common point to form the measurement volume. A particle or bubble passing through this volume scatters light having a Doppler-shifted frequency proportional to its velocity. Photodetectors pick up the scattered light and produce signals which are processed to yield the measured velocity.

The use of LDV measurement techniques in bubbly flows has been discussed in previous publications. Several researchers have used amplitude discrimination to measure liquid velocity by eliminating bubble signals from the LDV analysis. The basic premise of this method is that Doppler bursts from seed particles transported in the continuous liquid (cl) field are smaller than those originating from vapor-liquid interfaces. Sun and Faeth [8,9] used amplitude discrimination on $1 \mathrm{~mm}$ diameter bubbles in air-water jets with a single forward scatter detector. However, with a single detector it is impossible to make simultaneous liquid and vapor velocity measurements 
without special electronics. Neti and Colella [10] used two photodetectors in the forward and backward scatter directions and used standard processors to analyze the signals. Ohba et al. [11] and Ohba and Isoda [12] used a similar technique to measure phasic velocities in a $11.5 \mathrm{~mm}$ square duct at void fractions up to 0.31. In Vassallo et al. [13], an optical set-up is described in which a backscatter LDV probe is used to measure the bubble velocity, and a retroreflector/lens assembly is used in conjunction with the backscatter probe to measure liquid velocity. The retroreflector reflects forward scattered light from tracer particles present in the liquid phase back into the detection optics in the probe. Similar measurements were reported by Vassallo and Kumar [14], except that a separate forward scatter detector was used for the liquid velocity measurements.

For the current experiments, a backscatter fiber optic LDV probe was used to make the interfacial velocity measurements. The probe was equipped with a short focal length lens (122 $\mathrm{mm}$ ) to produce a measurement volume about $0.25 \mathrm{~mm}$ long. The probe was mounted on a traversing slide to enable motion perpendicular to the optically transparent test section faces. The position at which Doppler signals first appeared was judged to be the near wall (i.e., the wall closest to the probe). Measurements were taken across the test section thickness dimension with a positioning uncertainty of about $\pm 0.125 \mathrm{~mm}$. The beam power at the probe exit was between 40 and $75 \mathrm{~mW}$.

The Doppler signals were analyzed for velocity using a counter-timer signal processor with the processor gain adjusted to detect only the largest light scattering objects in the flow. For the case of bubbly flow, the largest scattering objects were bubbles; in annular flow, the largest scattering objects were droplets. Typical data rates for the velocity measurements were between 2 and $20 \mathrm{~Hz}$, depending on the measurement location inside the test section. Between 500 and 1000 velocity samples were obtained at each measurement location. LDV measurements were only taken across the near half of the test section because of the difficulty in obtaining good measurements as the beams penetrated further into the two-phase flow field within the test section.

Measurement of droplet velocity in the vapor core requires that the two LDV beams penetrate 
the annular liquid film and intersect to form a well defined measurement volume. Success depends on the thickness and steadiness of the film. At high void fractions and high flow rates, the liquid film is relatively thin, and LDV droplet measurements are found to be possible across most of the test section. As the void fraction or flow rate decreases, the film gets thicker and wavier, and the LDV measurements are more difficult to attain. At some moderate void fractions and flow rates, measurements of droplet velocity are only possible near the central plane of the test section. At void fractions less the 0.7 in annular flow, the irregularities in the film make it impossible to obtain measurements.

As for the HFA measurements described above, the uncertainty on LDV measurements is also based on the root-sum-square model for $95 \%$ confidence $( \pm 2 \sigma)$. The random uncertainty for these measurements is represented by

$$
\varepsilon_{s}= \pm \frac{2}{\sqrt{N}} \frac{u^{\prime}}{U}
$$

where $U$ and $u$ ' are the mean and rms velocity fluctuation, respectively, and $N$ is the total number of samples. Biases were estimated through consideration of velocity sampling, positioning, and random noise. Combining all these sources of uncertainty resulted in total uncertainty of up to $\pm 8.4 \%$ on local interfacial velocity. As for the HFA data, this uncertainty is somewhat higher near the duct walls.

\section{Flow Visualization}

Two instruments were used to visualize the two-phase flow field: a high speed video system and a digital image processing system. The high-speed video system was operated at 250 frames per second to obtain video images of the full duct and center region in all four windows along the length of the test section. Backlighting was used with a strobe light source illuminating a white diffuser. Vapor-liquid interfaces were very distinct, appearing dark-edged against the white background. With a $20 \mu \mathrm{sec}$ strobe flash, the fluid motion was effectively "frozen" for most low mass flux test conditions. The high-speed video zoom optics produced images with approximately 4 times magnification. It was difficult to obtain clear images for higher mass flow rates, since this flash time is significantly long relative to the shorter fluid passage time. Also, at high pressure, the 
vapor phase is often comprised of a very dense field of small bubbles. The large number of interfaces scatter the incident light to the extent that clear images are not attainable, even for relatively low flow conditions.

The digital image processing system consisted of a charge-injected device (CID) camera, frame grabber board and image processing software. The software enabled the raw images to be enhanced and objects of interest (e.g., bubbles in continuous liquid or droplets in continuous vapor) to be counted and sized. The flow field was back-illuminated using a flat light connected to a xenon flash source via a fiber optic bundle. The specially fabricated and polished fiber optic bundle provided uniform illumination intensity (within $+/-5 \%$ ) over the area of the flat light. Different optical arrangements were used depending on the required magnification. Examples of digital images obtained in various two-phase flow regimes are illustrated in Figure 3. In uniform bubbly flow at low pressure (Figure 3a), the bubble size was large; therefore, most of the test section could be imaged while providing enough magnification for the subsequent image analysis. In flows where bubble coalescence was beginning and a wide range of bubble sizes was observed (Figure 3b), approximately 8 times greater magnification was used to resolve most of the bubble population. The same magnification was used to observe the stratification between continuous liquid and continuous vapor when the test section was inclined (Figure $3 \mathrm{c}$ ). To image liquid droplets in annular flow (Figure 3d), additional magnification was required to resolve individual droplets as small as $0.1 \mathrm{~mm}$.

\section{Void Fraction Measurements}

Void fraction measurements were performed using both the gamma densitometer and the hotfilm probes. The gamma densitometer yields three kinds of measurements: (1) a cross-section averaged void fraction at selected test section elevations; (2) a transverse scan of the line-averaged void fraction profile across the wide (face) dimension of the test section at nearly any elevation; and (3) a transverse line-average scan of the profile across the narrow (side face) of the test section at selected elevations.

The hot-film anemometer probes provide two additional types of void fraction measurements. 
The local, point value of the void fraction can be measured at any $\mathrm{Z}$ position along the thickness (narrow) dimension of the test section, for two fixed test section elevations located in the upper two windows. These probes, located at the width center line of the test section faces, can provide measurements as close as $0.076 \mathrm{~mm}$ to the opposite heated window. In addition, two $\mathrm{Y}$ axis scanning probes are located between the second and third windows and between the third and fourth windows. These probes are centered in the narrow, thickness dimension of the test section. The line-averaged gamma densitometer scans across the wide test section faces in the $Y$ direction can be compared with the corresponding hot-film scans. Allowance must be made for the hot-film void fraction being only measured in the central plane, while the gamma measurements are lineaverages along the thickness or $\mathrm{Z}$ dimension. Also, the line-averaged gamma scans across the narrow thickness $(Z)$ direction can be roughly compared with the corresponding Z-scan hot-film measurements made at the central location. In the remainder of this section typical results are shown for each of these types of measurements. Although both the gamma densitometer and hotfilm anemometer methods were used in all two-phase flow regimes, the data discussed focuses on subcooled boiling. flow with one side of the test section heated, and annular flow with and without wall heating.

\section{Cross-Section Average Void Fraction}

These measurements are the easiest to make and the most accurate of all of the gamma densitometer measurements. The wide beam from the gamma source uniformly illuminates an entire cross-sectional level of the test section. Because the beam height is about $2.5 \mathrm{~cm}$ at the test section location, a streamwise spatial average over this length is implicit.

Representative cross-section average void fraction results are provided in Figure 4 for $P=$ 2.4 MPa, w $=104 \mathrm{~kg} / \mathrm{hr}$, with subcooled liquid $\mathrm{R}-134 \mathrm{a}$ entering the bottom of the test section. Wall heating was applied uniformly at a net rate of $3.4 \mathrm{~kW}$. At the lowest two measurement positions $\left(X / D_{h}=24.4\right.$ and $43.7 ; X / L=0.10$ and 0.18 , respectively), the measured density is greater than the liquid density at the saturation temperature. Hence, at these locations the flow is still single-phase liquid and $\alpha=0$. Upon moving to $X / D_{h}=87.3(X / L=0.36)$, the void fraction becomes nonzero. Beyond this measurement location, there is a monotonic increase in void fraction with increasing streamwise position, to a maximum cross-sectional average value of 0.88 . 
The average void fraction profiles are vitally important to evaluate the overall capability of the models, in particular the net vapor generation which allows the initial transition from single-phase to two-phase flow to occur. However, in order to identify flow regime transitions, local distributions of void fraction need to be measured.

\section{Yoid Fraction Distributions}

The distribution of the void fraction across the narrow test section dimension ( $\mathrm{Z}$ axis scans) clearly illustrates the flow regime which is present. Line-average void fraction distributions across the narrow dimension of the R-134a test section are illustrated in Figure 5, for the same experimental run as presented in Figure 4. At the first position for which a nonzero cross-sectional average void fraction was measured $\left(X / D_{h}=87.3 ; X / L=0.36\right)$, the vapor phase is clearly concentrated in the near-wall regions, with significant subcooled liquid still present at the duct center. A wall-peaked profile is also observed at $X / D_{h}=106.5(X / L=0.44)$, but the local liquid temperature is higher so that interfacial heat transfer does not result in complete bubble condensation. It should be noted that for high test section pressures (2.4 MPa in R-134a), the bubbles produced by wall heating are small and bubbly flow can persist for void fractions up to and sometimes beyond 0.6 . In the subcooled and low void, bubbly flow range, these distributions tend to be peaked near the walls as previously noted by several investigators (e.g., Nakoryakov et al. [15]; Serizawa and Kataoka [16]; Liu and Bankoff [17]). This is believed to be a result of the transverse lift force which drives the small, spherical bubbles toward the walls. When the small bubbles grow in size, and become non-spherical, distorted and oscillatory, the lift force changes direction (Sekoguchi et al. [18]; Kariyasaki [19]; Zun [20]) and the bubbles move away from the wall. This tends to concentrate the vapor near the duct center, thereby producing a void fraction profile which is center-peaked. The bubble diameter at which the bubble ceases to be spherical is proportional to $\sqrt{\sigma /(\Delta \rho g)}$. The constant of proportionality can be determined from flow visualization experiments such as the ones shown in Figure 3. The lift force model is based on potential flow theory, thus in the four-field representation, the lift coefficient is allowed to change signs at a critical bubble diameter so that the change in the void fraction profile from wall-peaked to center-peaked can occur.

At higher void fraction these bubbles coalesce, grow to the size of the duct, the average void 
fraction increases, and the flow becomes transitional in nature between bubbly flow and annular flow. This bubble growth and coalescence result in center-peaked void fraction profiles between $X / D_{h}=106.5$ and $150.1(X / L=0.44$ and 0.62 , respectively). Based on these profiles and similar profiles obtained for different pressures and flow conditions, the lift coefficients with the appropriate signs can be obtained for the lift force model. Here, a mixture of continuous vapor slugs separated by liquid bridges and dispersed vapor bubbles flow together in a continuous liquid field. The two-phase flow transition models should capture these effects. As the average void fraction increases further, coalescence of smaller bubbles (dv) and the conversion of $\mathrm{dv}$ to $\mathrm{cv}$ is complete, forming a vapor core with droplets, bounded by a thin liquid film on the walls at $X / D_{h}=$ 212.9 and $232.2(X / L=0.87$ and 0.95 , respectively). The void distributions which are nearly flat in the proximity of the duct centerline, with significant gradients near the walls. This is indicative of the presence of fairly uniformly distributed liquid droplets in the vapor core, and a wall-bounded continuous liquid film. The void fraction gradients at the walls result from bubbles (dv field) dispersed in the $\mathrm{cl}$ field and the presence of interfacial waves on the liquid film. These waves have a velocity intermediate in magnitude between the liquid film and continuous vapor velocities.

Void fraction $\mathrm{Z}$ axis distributions in the narrow, test section thickness dimension are also routinely made using hot-film anemometer probes. These probes have an advantage over the gamma densitometer in that true point measurements (as opposed to line-averaged) can be performed. In addition, the probe can be positioned as close as $0.076 \mathrm{~mm}$ to the heated wall, whereas the gamma transmission technique cannot provide reliable results closer than $0.25 \mathrm{~mm}$.

One of the flow regimes studied using HFA was subcooled boiling. For these experiments only one face of the test section was heated (to provide better optical and laser access from the opposite side). The HFA measurements were made in the second heated window at an elevation of $X D_{h}=118(X / L=0.48)$ in the central plane. Representative results are shown in Figure 6(a) for inlet temperatures ranging from $32{ }^{\circ} \mathrm{C}$ to $66^{\circ} \mathrm{C}$, with fixed system pressure of $2.4 \mathrm{MPa}$ and a mass flow rate of $106 \mathrm{~kg} / \mathrm{hr}$. These five temperatures correspond to inlet subcooling values of 10 to 44 ${ }^{\circ} \mathrm{C}$ for which the flow fields cover the flow regime from subcooled to saturated boiling. The heated test section wall is at the left side of the figure. Although there is no nucleation on the right wall, some wall peaking of the void can be noted for high inlet subcooling for the two lowest inlet 
temperature runs. Once again, this suggests that the small spherical bubbles are attracted to the walls, and that this mechanism should be accounted for through the lift force model. It is also noted that a transition occurs between near-wall peaked void fraction profiles to center-peaked profiles as the inlet temperature and resulting average void fraction increases. At the highest inlet temperature, the measured cross-sectional average void fraction is 0.56 and flow visualization results clearly showed that significant coalescence resulted in highly non-spherical bubbles, similar to Figure 3b. Figure 6(b) shows line-averaged gamma densitometer void profiles for the same flow conditions. As a result of both the line averaging and the finite spatial size of the gamma beam, the near-wall void fraction peaks are less clearly resolved. For this kind of measurement, the HFA probe is the preferred instrument, due to its spatial resolution. However, the gamma densitometer profiles of 6(b) are very similar to those in 6(a) and, therefore, provide added confidence in the local HFA void fraction data.

Another flow regime of interest in the R-134a test program was the annular flow regime without wall heating. For these experiments, the two-phase flow field of interest was produced using heaters located upstream of the test section inlet. The absence of wall vapor generation makes it easier to apply optical measurement methods (LDV, flow visualization), as well as to evaluate momentum exchange models without considering heat transfer effects. Representative HFA and GDS void fraction profiles, acquired across the narrow test section dimension, are presented in Figure 7 for a fixed nominal pressure and flow rate of $2.4 \mathrm{MPa}$ and $106 \mathrm{~kg} / \mathrm{hr}$. For the HFA scans, data were acquired only to about the duct centerline because of the expected flow field symmetry. The inlet heating was varied to produce a range of void fractions, as determined by the wide beam gamma densitometer measurement near the test section exit. The local HFA profiles for average void fractions of 0.75 and 0.85 indicate a maximum vapor volume fraction at the duct centerline, similar to the transitional flow profiles illustrated in Figure 5. Upon increasing the void fraction further, the profiles become progressively flatter. For the two highest void fraction conditions, the absence of a significant near-wall gradient suggests that for this pressure and flow condition the liquid film is very thin, less than $6 \%$ of the narrow duct dimension. Note that for the same flow condition, the GDS data lie lower than the HFA data as the former averages the void fraction over the entire test section width, and encounters liquid collected along the duct edges. 


\section{Dispersed and Continuous Phase Velocity Measurements}

In addition to the void distributions, reliable measurements of the phasic velocities are critical to the development and validation of two-phase flow models. There is a direct relationship between the drag coefficient and the rise velocity of an individual bubble. By measuring bubble velocity using either LDV or HFA, drag models can be improved. Bubble and droplet velocity measurements also indirectly support other models in different flow regimes. For example, the bubbles trapped in the thin liquid film travel at slightly higher velocity than the liquid film itself. With some understanding of the magnitude of the liquid velocity in the film, wall shear and annular flow interfacial models can be developed.

This section discusses and compares two methods for measuring phasic velocity. The first technique is simply based on the time-of-flight of the dispersed phase (bubble or droplet) between the two sensors in a twin-sensor HFA probe as previously described. In the second method, a laser Doppler velocimeter is used in the backscatter light collection mode to measure the bubble or droplet velocity. Figure 8a compares bubble velocity measurements made using these two techniques. These measurements were made as a part of the subcooled boiling flow experiments for which representative HFA and GDS void fraction distributions were shown previously in Figure 6. The agreement between the LDV and HFA data sets was generally good for all subcooled boiling conditions investigated. It is important to note that the bubble velocity profiles are quite flat, even for cases where a significant void fraction peak was measured near the heated wall.

A later experimental test sequence involved adiabatic (i.e., no wall heating) annular flow. At average void fractions exceeding 0.7 , the two-phase flow field is comprised, at least in part, of dispersed liquid droplets transported by a turbulent vapor core, with co-flowing liquid films bounded by the test section walls. Figure $8 \mathrm{~b}$ shows droplet velocity measurements for three different average void fraction at $\mathrm{P}=2.4 \mathrm{MPa}$ and $\mathrm{w}=106 \mathrm{~kg} / \mathrm{hr}$, using the HFA and LDV methods. Again, for this flow regime, the agreement between the two data sets was generally good. The reasonable agreement between measurements obtained with the intrusive HFA and non-intrusive LDV techniques confirms that the former does not significantly affect the local two- 
phase flow structure.

\section{Continuous Liquid Velocity in Bubbly Flow}

Relative velocity between the continuous and dispersed phases is found in some form in virtually all of the inter- and intra-field force terms in all the regimes. For example, the lift and drag forces on the dispersed phases and the interfacial momentum terms in annular flow all require knowledge of the relative phasic velocities. This section discusses simultaneous measurements of liquid and vapor velocities in the bubbly flow regime using a specialized LDV instrumentation technique called pedestal amplitude discrimination.

As a particle or bubble passes through the LDV measurement volume, it produces a signal containing a pedestal component and a Doppler component. The Doppler component contains the frequency which is directly related to the particle velocity. The pedestal height represents the magnitude of the light flux reaching the photo-detector; it increases as the diameter of the scattering object increases. Typically, the liquid phase is seeded by adding $5 \mu \mathrm{m}$ diameter latex particles. Because the diameter of a bubble is larger than a typical seed particle (on the order of 100 times larger) there is a difference between the bubble pedestal amplitude and the seed pedestal amplitude. By setting an appropriate threshold on a pedestal height discriminator, it is possible to identify which signals are generated from bubbles and which are generated from seed.

One shortcoming of this method is the possibility of bubbles producing small amplitude signals. Martin and Abdelmessih [21] analyzed signals from individual rising bubbles, and have determined that, in addition to a large refractive burst, there may be two smaller reflective bursts occurring from each bubble. These could contaminate the small amplitude signals from the seed. Also, because of the measurement volume's Gaussian profile, it is possible to get a small amplitude signal from a large bubble if that bubble crosses the edge of the measurement volume. Therefore, some fraction of bubble signals will contaminate the liquid velocity measurement.

From a practical point of view, it is still possible to use the amplitude discrimination method if the bubble contamination rate is small compared to the liquid data rate. For example, if the liquid seed particle data rate is 10 times higher than the contamination rate due to bubbles, $90 \%$ 
accuracy is obtained. While it is difficult to quantify the bubble contamination rate, it may be bounded by equating it with the rate of bubble passing through the measurement volume. This gives an indication of the liquid data rate required for acceptable measurements.

\section{Simultaneous Liquid and Vapor Velocity Measurements}

An example of liquid and bubble velocity data obtained using amplitude discrimination is shown in Figure 9. The measurements were taken across the width of the test section along the center plane at a streamwise position of $X / D_{h}=162.4(X / L=0.67)$. During data acquisition, the pedestal discriminator was set while in single-phase liquid so that only 5-10\% of the liquid signal amplitudes were rejected. The more intense forward scatter LDV arrangement (where the detector faces the probe) was chosen for liquid velocity measurements because of the need for a maximum data rate. The liquid data rate (from seed particles, without bubbles) was approximately $10 \mathrm{KHz}$. Between two and four forward scatter measurements were taken at each point, for a sample size of 10,000 each. The measurements were analyzed off-line to determine an average liquid velocity for each of nine $Y$ positions across the test section width. Low gain backscatter bubble measurements were taken as well. Because the flow rates were low, recirculation existed near the right and left test section walls; this shows up in Figure 9 as negative liquid velocities.

Measurements of the single-phase liquid velocity are provided to show the effect that the gas phase has in increasing the magnitude of the liquid velocity.

\section{Vapor Bubble and Liquid Droplet Size Measurements}

The mean size of the dispersed phase (i.e., bubbles in liquid or droplets in vapor) can be determined from HFA measurements of local void fraction, interfacial velocity and interfacial frequency. For example, assuming a cylindrical control volume is centered around the HFA probe and the probe is exposed to only the continuous liquid (cl) and dispersed vapor (dv) fields, the local vapor volumetric flow rate through this control volume may be written as

$$
Q_{v}=Q_{b} f_{b}
$$

where $Q_{b}$ and $f_{b}$ are, respectively, the average vapor bubble volume and bubble frequency. Alternatively, 


$$
\dot{Q}_{v}=V_{b} A_{b}
$$

where $V_{b}$ and $A_{b}$ are the time-average bubble velocity and the average bubble cross-sectional area. Assuming that the ratio of vapor volume to total volume is nearly the same as the area ratio,

$$
\alpha=\frac{A_{b}}{A_{T}}
$$

where $\alpha$ is the volume fraction of the dispersed vapor field and $A_{T}$ is the total cross-sectional area of the cylindrical control volume. Substituting Equation 9 and equating Equations 7 and 8 yields,

$$
Q_{b} f_{b}=V_{b} \alpha A_{T}
$$

From Equation 10, a spherical equivalent bubble diameter can be obtained as

$$
d_{b}=1.5 \frac{V_{b} \alpha}{f_{b}}
$$

where $\alpha$ and $f_{b}$ are measured by the upstream sensor of the HFA probe, and the time-average bubble velocity $V_{b}$ is obtained from the cross-correlation between the two HFA output voltage signals. An expression similar to Equation 11 is used in annular flows to calculate the mean diameter of liquid droplets transported in the continuous vapor core. By substituting 1- $\alpha$ for $\alpha$ and droplet velocity and frequency for $V_{b}$ and $f_{b}$ :

$$
d_{d}=1.5 \frac{V_{d}(1-\alpha)}{f_{d}}
$$

In Figure 10a, local mean bubble diameter profiles are presented for subcooled boiling flow with one wall heated; use is made of local HFA void fraction and velocity data (Figures 6a and 8a, respectively) to calculate $d_{b}$ via Equation 11 . For the three lowest inlet liquid temperatures, the data profiles are nearly flat across the duct spacing dimension, and the magnitude of the diameter is only weakly dependent on the level of inlet subcooling. Since the mean diameters calculated for these conditions are all considerably less than the duct spacing dimension, it is likely that the vapor field is primarily comprised of dispersed spherical bubbles, with little or no coalescence occurring in the direction normal to the heated wall. Upon increasing $T_{\text {in }}$ to $66^{\circ} \mathrm{C}$, the structure of the flow changes dramatically. The maximum calculated diameter exceeds $3 \mathrm{~mm}$ and there is a large gradient from the near-wall to centerline region. For this condition, planar bubbles are 
produced due to the confinement of the quartz windows which define the narrow (Z) test section dimension. Comparing this result with Figure $6(\mathrm{a})$, we note that at the $6{ }^{\circ} \mathrm{C}$ inlet condition the void fraction profiles changed from near-wall peaked to center-peaked distributions.

In Figure 10b, the variation in droplet size across the duct spacing dimension is plotted for adiabatic annular flow with $w=106 \mathrm{~kg} / \mathrm{hr}$ and $P=2.4 \mathrm{MPa}$. The calculation of droplet size via Equation 12 makes use of the HFA void fraction and velocity measurements presented in Figures $7 \mathrm{a}$ and $8 \mathrm{~b}$, respectively. Droplet size calculations are reported for $Z / t>0.2$ which corresponds to the vapor core region. At these locations, the droplet field is removed from the influence of the wavy liquid film (see Figure 7a). The most obvious trend is that the droplet diameter generally decreases with increasing average void fraction. For the cases with $\alpha=0.75$ and 0.85 where center-peaked void fraction profiles were observed, the droplets appear to be larger in the vicinity of the co-flowing liquid film and smaller near the duct centerline. The droplets are likely generated near the interface between liquid film and continuous vapor, due to the shearing of the roll waves. As discussed by Kocamustafaogullari et al. [22], droplet size is controlled by the interaction between the droplet and the surrounding turbulent gas stream. Hence, newly entrained droplets measured near the liquid film are larger, while droplets at the duct centerline are subjected to turbulent break-up and would, on average, be smaller. Also, because $d_{d}$ varies as 1 $\alpha$, the shape of the diameter profiles tend to follow a trend which is the inverse of that observed for the local void fraction, as in most cases the gradients in measured droplet frequency and velocity are small for $Z / t>0.2$.

\section{Summary}

Continuing advances in computational methods for prediction of gas-liquid two-phase flow necessitates the development of a comprehensive experimental database to support mechanistic modeling and code qualification. Because of the need for measurements with improved spatial and temporal resolution and better accuracy, a program was undertaken to improve existing twophase flow instrumentation techniques. The work summarized in this paper describes advances made in gamma densitometry, hot-film anemometry and laser Doppler velocimetry for local measurements of void fraction, phasic velocities, and bubble and droplet size. The use of a low 
pressure and temperature modeling fluid (R-134a) in a vertical duct permits full optical access to visualize the two-phase flow fields in bubbly, slug, transitional and annular regimes. A digital flow visualization system is used to qualitatively characterize the flow, and provide additional information on bubble and droplet size. Whenever possible, simultaneous measurements with multiple instruments are performed to confirm data trends, and cross-qualify void fraction and velocity data.

The local results presented in this paper illustrate how the spatially resolved data requirements needed to support a two-fluid modeling and code development program may be met. Examples of "separate effects" investigations for model development include subcooled boiling with one test section wall heated, and adiabatic annular flow with no wall heat addition. The data obtained in these two distinctly different flow regimes illustrate the ability to resolve various void fraction and interfacial velocity gradients, and provide information on the mean size of vapor bubbles in continuous liquid, and liquid droplets in continuous vapor. The development of improved measurement techniques has provided new information to understand and model physical phenomena in two-phase flow, including net vapor generation, lift and drag forces, bubble coalescence and droplet entrainment. It is anticipated that further advances in computational tools for two-phase flow design will ultimately rely on continuing improvements in the ability to measure local flow field characteristics.

\section{Acknowledgments}

The authors acknowledge the valuable contributions of Messrs. W.O. Morris, D.M. Considine, L. Jandzio, C.W. Zarnofsky and E. Hurd in the operation of the test facility, and advanced instrumentation data acquisition and analysis. Mr. S.W. D' Amico contributed to development of the hot-film anemometer probe traversing and data acquisition systems. 


\section{References}

[1] Dix GE. Vapor void fractions for forced convection with subcooled boiling at low flow rates. Ph.D. Thesis. University of California, Berkeley. 1971.

[2] Shiralkar BS, Lahey RT, Jr. Diabatic local void fraction measurements in freon-114 with a hotwire anemometer. ANS Trans. 1972; 15: 880.

[3] Hasan A, Roy RP, Kalra SP. Some measurements in subcooled flow boiling of refrigerant-113, ASME J. Heat Trans. 1991; 113: 216-223.

[4] Carvalho R, Bergles AE. The pool nucleate boiling and critical heat flux of vertically oriented, small heaters boiling on one side. Rensselaer Polytechnic Institute (Troy, New York). Heat Transfer Laboratory Report HTL-12, 1992.

[5] Trabold TA, Moore WE, Morris WO, Symolon PD, Vassallo PF, Kirouac GJ. Two phase flow of freon in a vertical rectangular duct. Part II: Local void fraction and bubble size measurements. In: Celik I et al., editors. Experimental and computational aspects of validation of multiphase flow CFD codes. ASME, 1994; FED 180: 67-76.

[6] Jones OC, Zuber $N$. Use of a cylindrical hot-film anemometer for measurement of two-phase void and volume flux profiles in a narrow rectangular channel. In: Heat transfer: Research and application. AIChE, 1978; 74: 191-204.

[7] Trabold TA, Moore WE, Morris WO. Hot-film anemometer measurements in adiabatic twophase refrigerant flow through a vertical duct. In: Proceedings of the ASME Fluids Engineering Division Summer Meeting. Vancouver (British Columbia, Canada). ASME, 1997: Paper FEDSM97-3518.

[8] Sun T-Y, Faeth GM. Structure of turbulent bubbly jets - I. Methods and centerline properties. Int. J. Multiphase Flow, 1986; 12: 99-114.

[9] Sun T-Y, Faeth GM. Structure of turbulent bubbly jets - I. Phase property profiles. Int. J. Multiphase Flow, 1986; 12: 115-126.

[10] Neti S, Colella GM. Development of a fiber optic Doppler anemometer for bubbly two-phase flows. EPRI Report NP-2802, 1983.

[11] Ohba K, Tsutomu Y, Matsuyama H. Simultaneous measurements of bubble and liquid velocities in two-phase flow using laser Doppler velocimeter. Bulletin of JSME, 1986; 29: 2487-2493.

[12] Ohba K, Isoda J. Role of bubbly behavior in turbulence structure of vertical bubbly flow Simultaneous measurement of bubble size, bubble velocity and liquid velocity using phase Doppler method. In: Jones OC, Michiyoshi I, editors. Dynamics of two-phase flows. CRC Press, 1992: 347-358. 
[13] Vassallo PF, Trabold TA, Moore WE, Kirouac GJ. Measurement of velocities in gas-liquid two-phase flow using laser Doppler velocimetry. Experiments in Fluids, 1993; 15: 227-230.

[14] Vassallo PF, Kumar, R. Liquid and gas velocity measurements using LDV in air-water duct flow. In: Proceedings of the ASME Heat Transfer and Fluids Engineering Divisions. ASME, 1995; HTD-321/FED-233: 487-495.

[15] Nakoryakov VE, Kashinsky ON, Burdukov AP, Odnoral VP. Local characteristics of upward gas-liquid flows. Int. J. Multiphase Flow; 7: 63-81.

[16] Serizawa A, Kataoka I. Phase distribution in two-phase flow. In: Proceedings of the ICHMT International Symposium on Transient Phenomena in Multiphase Flow. Dubrovnik (Yugoslavia): 1987: 179-224.

[17] Liu TJ, Bankoff SG. Structure of air-water bubbly flow in a vertical pipe: I - Liquid mean velocity and turbulence measurements. ASME, 1990; FED-99/HTD-155: 9-17.

[18] Sekoguchi K, Fukui H, Sato, Y. Flow characteristics and heat transfer in vertical bubble flow. In: Bergles AE, Ishigai S, editors. Two Phase Flow Dynamics. Hemisphere, 1981.

[19] Kariyasaki A. Behavior of a single bubble in a liquid flow with a linear velocity profile. In: Proceedings of the ASME-JSME Thermal Engineering Joint Conference, 1987; 5: 261-267.

[20] Zun I. Transition from wall void peaking to core void peaking in turbulent bubbly flow. Proceedings of the ICHMT International Symposium on Transient Phenomena in Multiphase Flow. Dubrovnik (Yugoslavia): 1987.

[21] Martin W, Abdelmessih A. Characteristics of laser-Doppler signals from bubbles. Int. J. Multiphase Flow, 1981; 7: 439-459.

[22] Kocamustafaogullari G, Smits SR, Razi J. Maximum and mean droplet sizes in annular twophase flow. Int. J. Heat Mass Transfer, 1994; 37: 955-965. 
Table 1: Summary of Parameters to be Measured and Applicable Measurement Techniques

\begin{tabular}{|l|l|l|}
\hline Parameter to be Measured & Measurement Technique & \multicolumn{1}{|c|}{ Models Supported } \\
\hline \hline $\begin{array}{l}\text { cross-section averaged void } \\
\text { fraction }\end{array}$ & $\begin{array}{l}\text { gamma densitometer } \\
\text { (wide beam) }\end{array}$ & net vapor generation \\
\hline $\begin{array}{l}\text { line-averaged void fraction } \\
\text { distributions }\end{array}$ & $\begin{array}{l}\text { gamma densitometer } \\
\text { (narrow beam) }\end{array}$ & integrated models, lift force \\
\hline $\begin{array}{l}\text { macro- and micro-photo- } \\
\text { graphic analog and digital } \\
\text { images }\end{array}$ & $\begin{array}{l}\text { high speed video, digital flow } \\
\text { visualization }\end{array}$ & $\begin{array}{l}\text { coalescence, bubble and drop } \\
\text { size, bubbly flow drag force } \\
\text { from rise velocity }\end{array}$ \\
\hline $\begin{array}{l}\text { local void fraction distribu- } \\
\text { tions }\end{array}$ & hot-film anemometer & $\begin{array}{l}\text { multi-dimensionality, wall } \\
\text { shear, interfacial shear }\end{array}$ \\
\hline droplet size & hot-film anemometer & $\begin{array}{l}\text { drop size, net entrainment } \\
\text { rate, liquid bridge breakup }\end{array}$ \\
\hline $\begin{array}{l}\text { dispersed bubble and droplet } \\
\text { velocity }\end{array}$ & hot-film anemometer \\
laser Doppler velocimeter & $\begin{array}{l}\text { bubbly wall shear, bubbly } \\
\text { drag, droplet drag, net entrain- } \\
\text { ment rate }\end{array}$ \\
\hline $\begin{array}{l}\text { simultaneous bubble and liq- } \\
\text { uid velocity }\end{array}$ & laser Doppler velocimeter & bubbly drag \\
\hline
\end{tabular}


$\mathrm{P}=$ pressure tap location
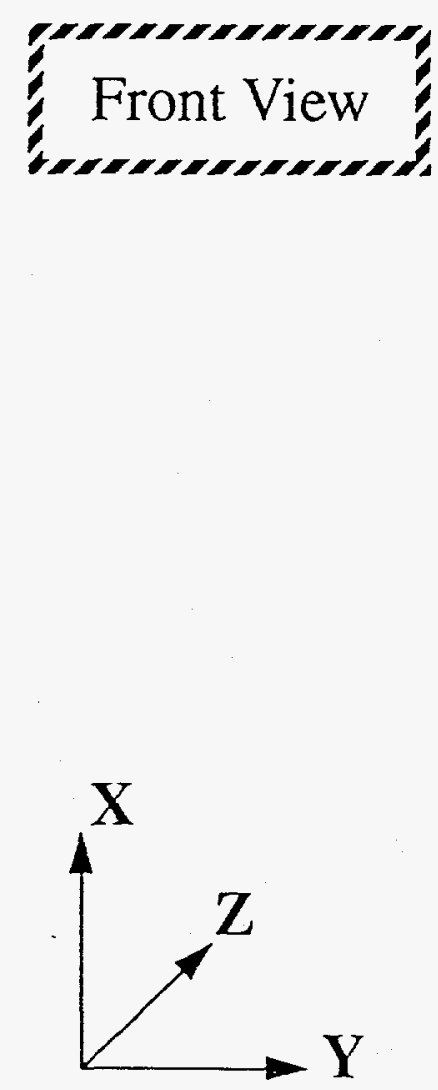

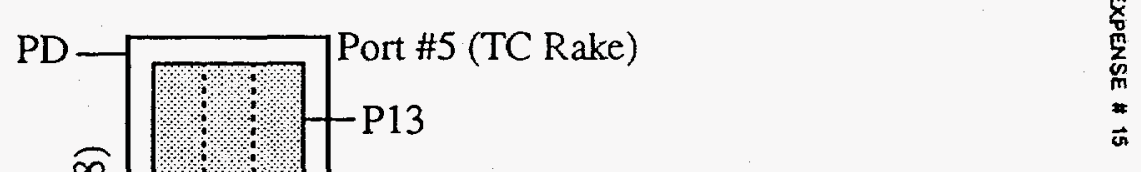

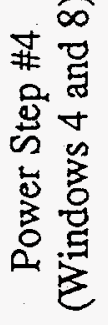

\#

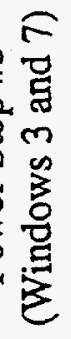

P7

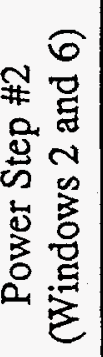

Port \#3

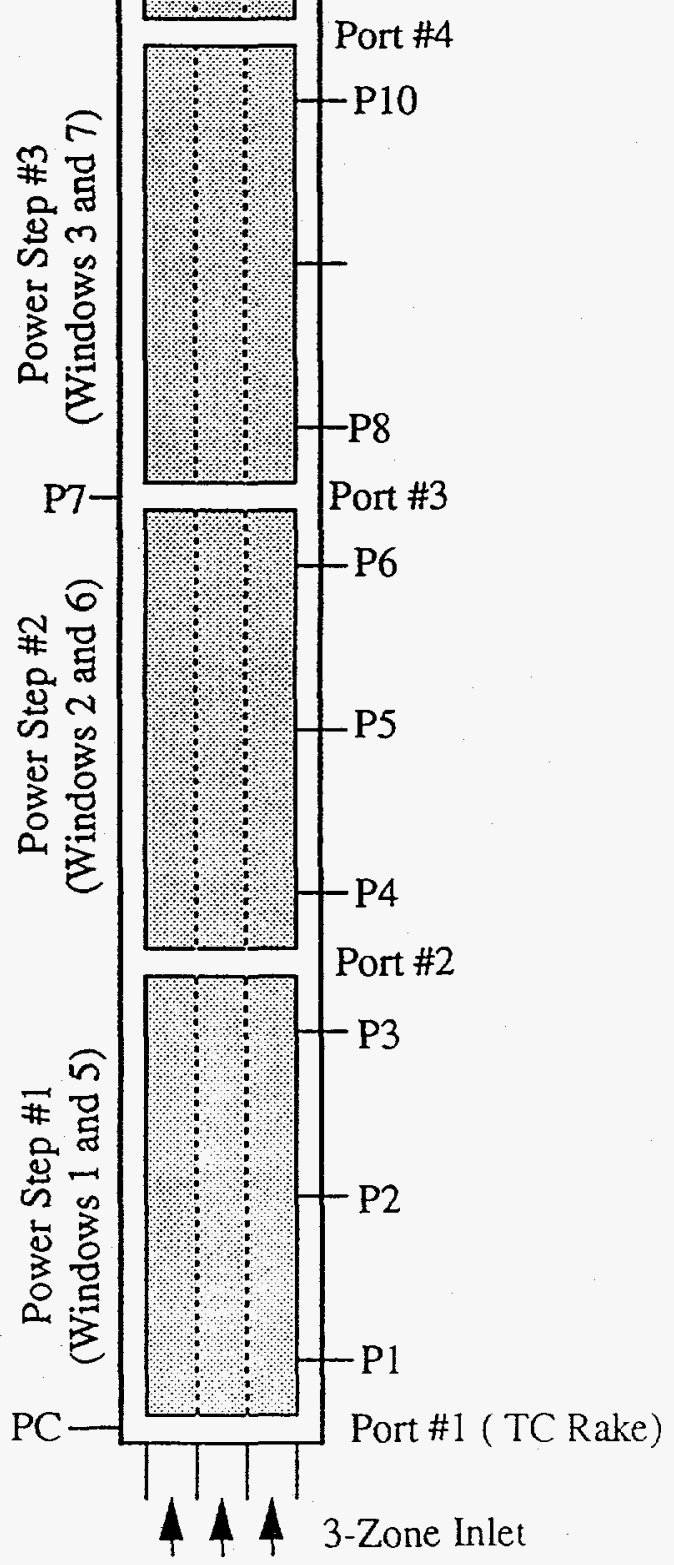

Figure 1 - Test Section and Measurement Locations 

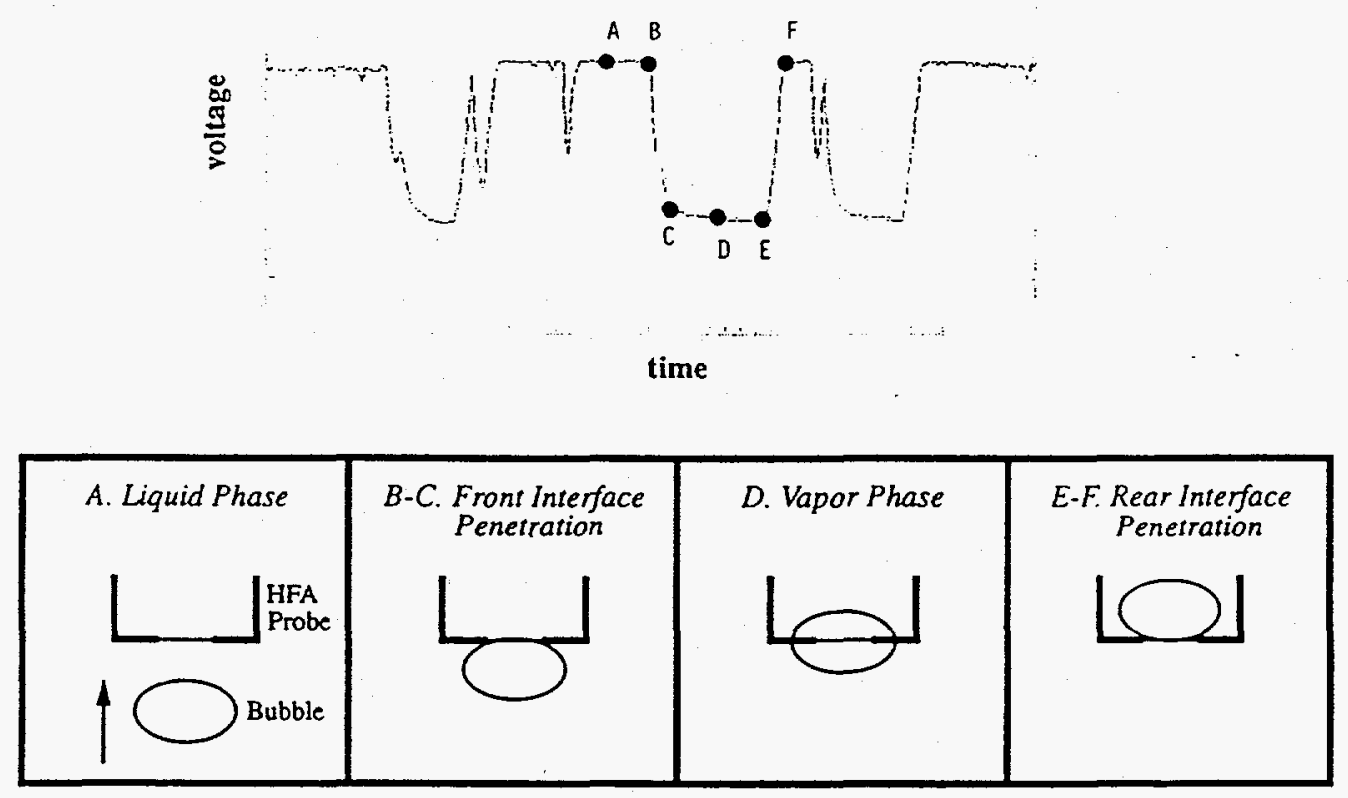

(a)

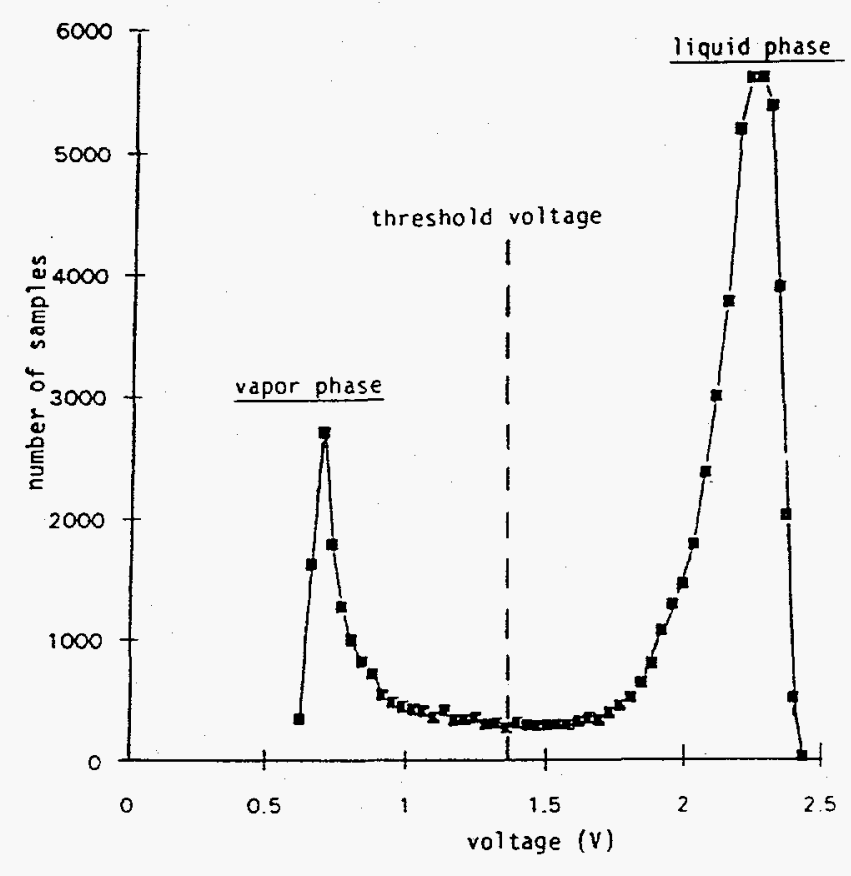

(b)

Figure 2 - (a) HFA voltage signal and bubble-probe interaction in bubbly flow;

(b) voltage histogram 


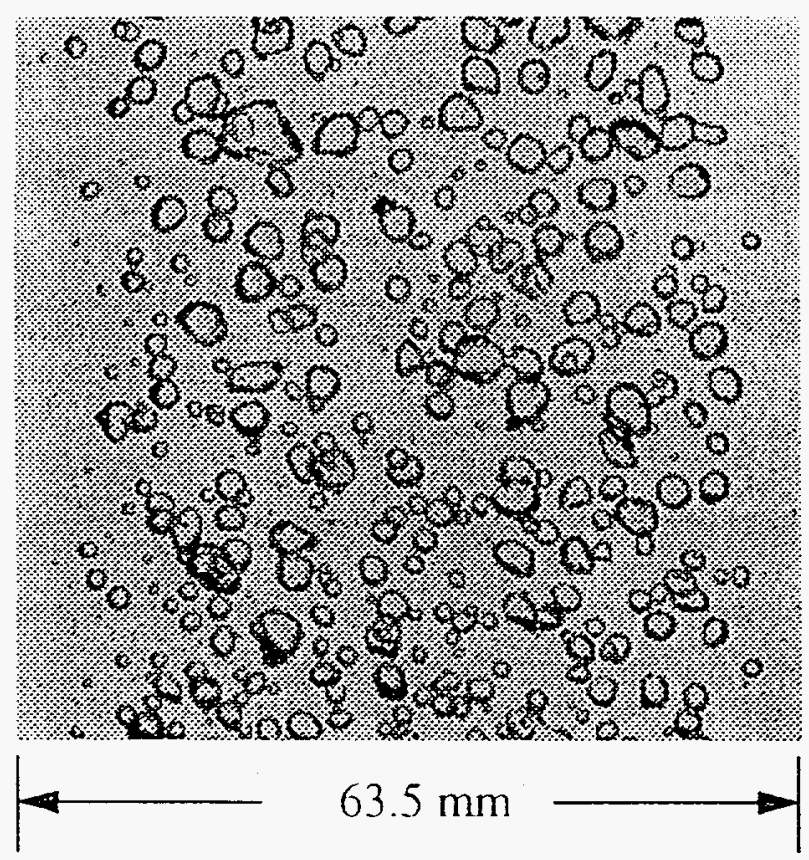

(a)

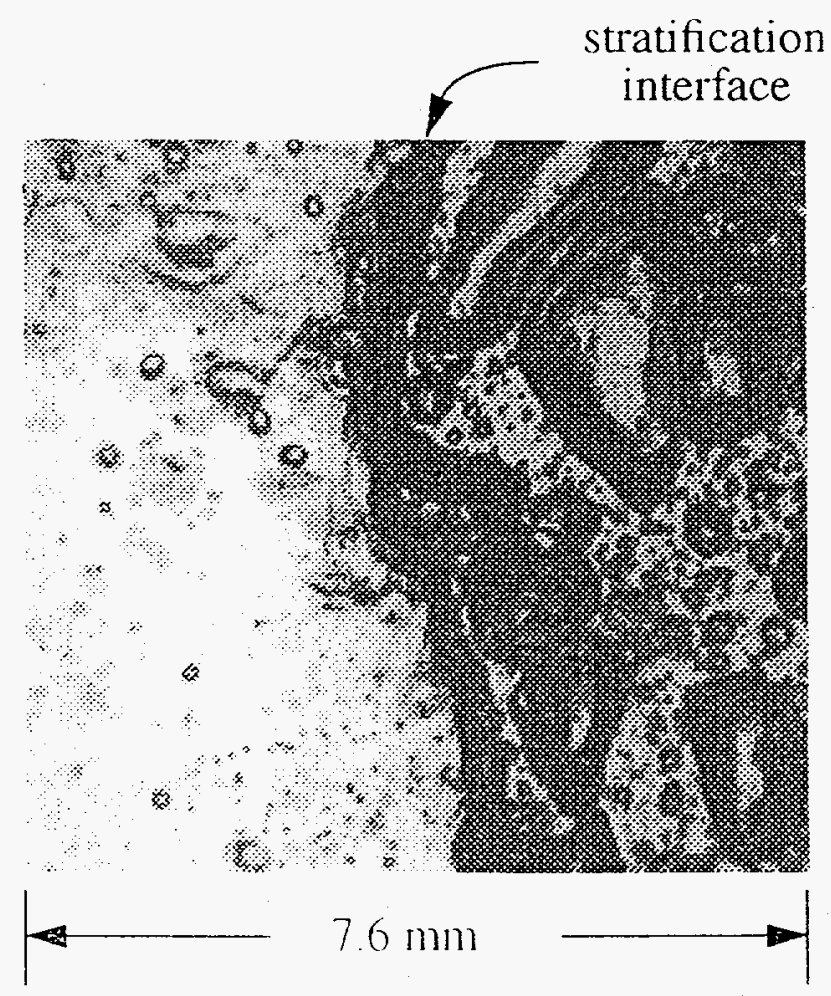

(c)

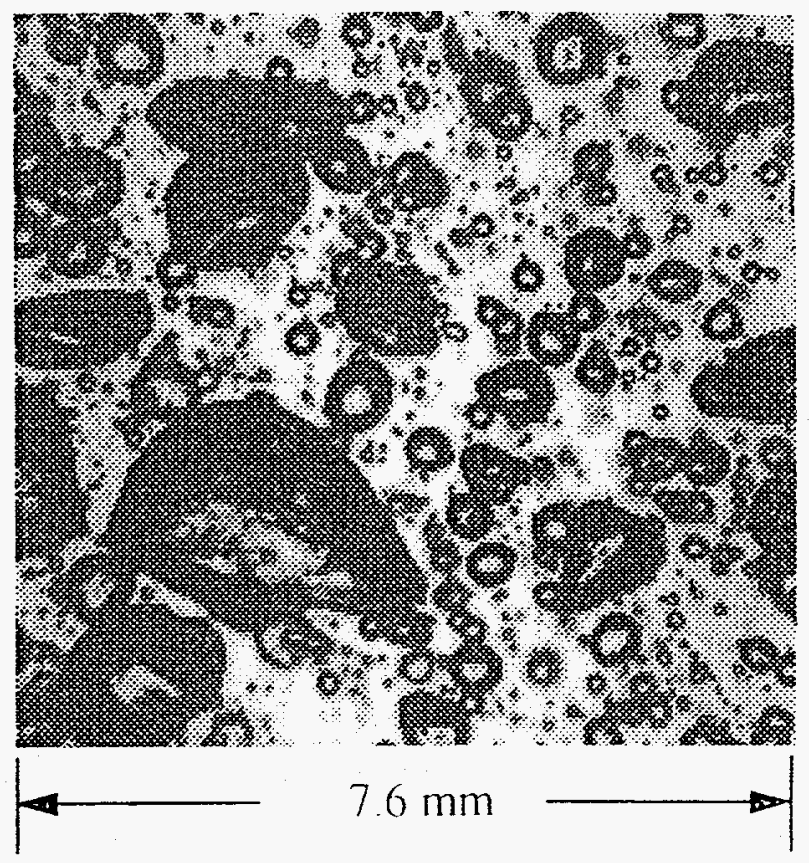

(b)

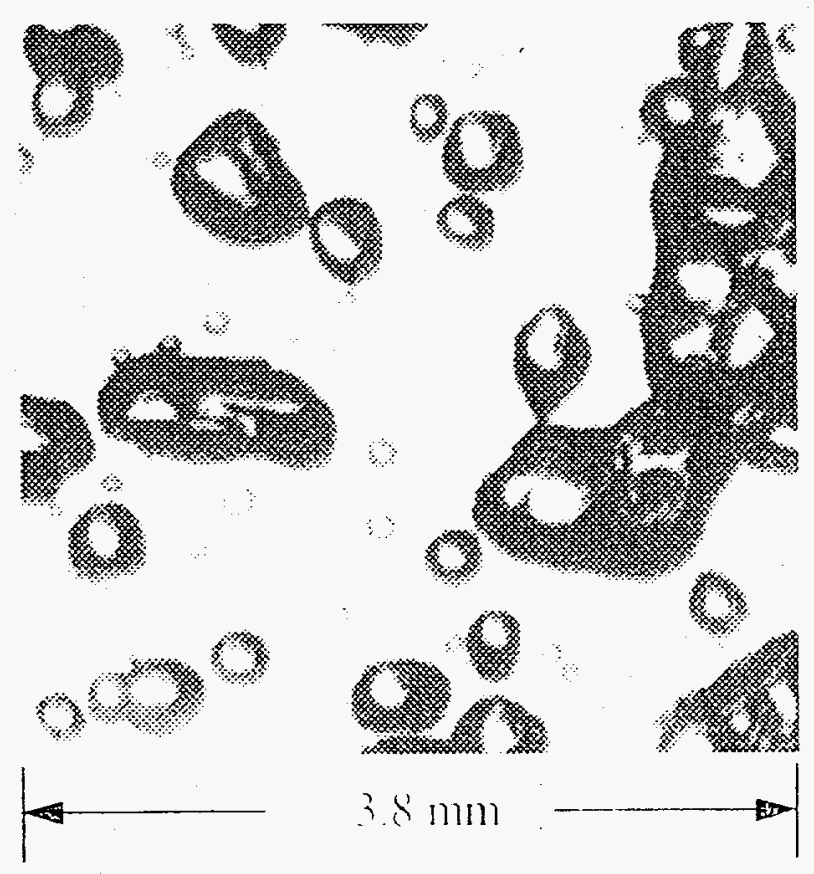

(i)

Figure 3 - Digital Images of Two-Phase Flow

(a) buhbly flow: (b) slug flow: (c) stratified flow: (d) liqual dropless in annular flow 


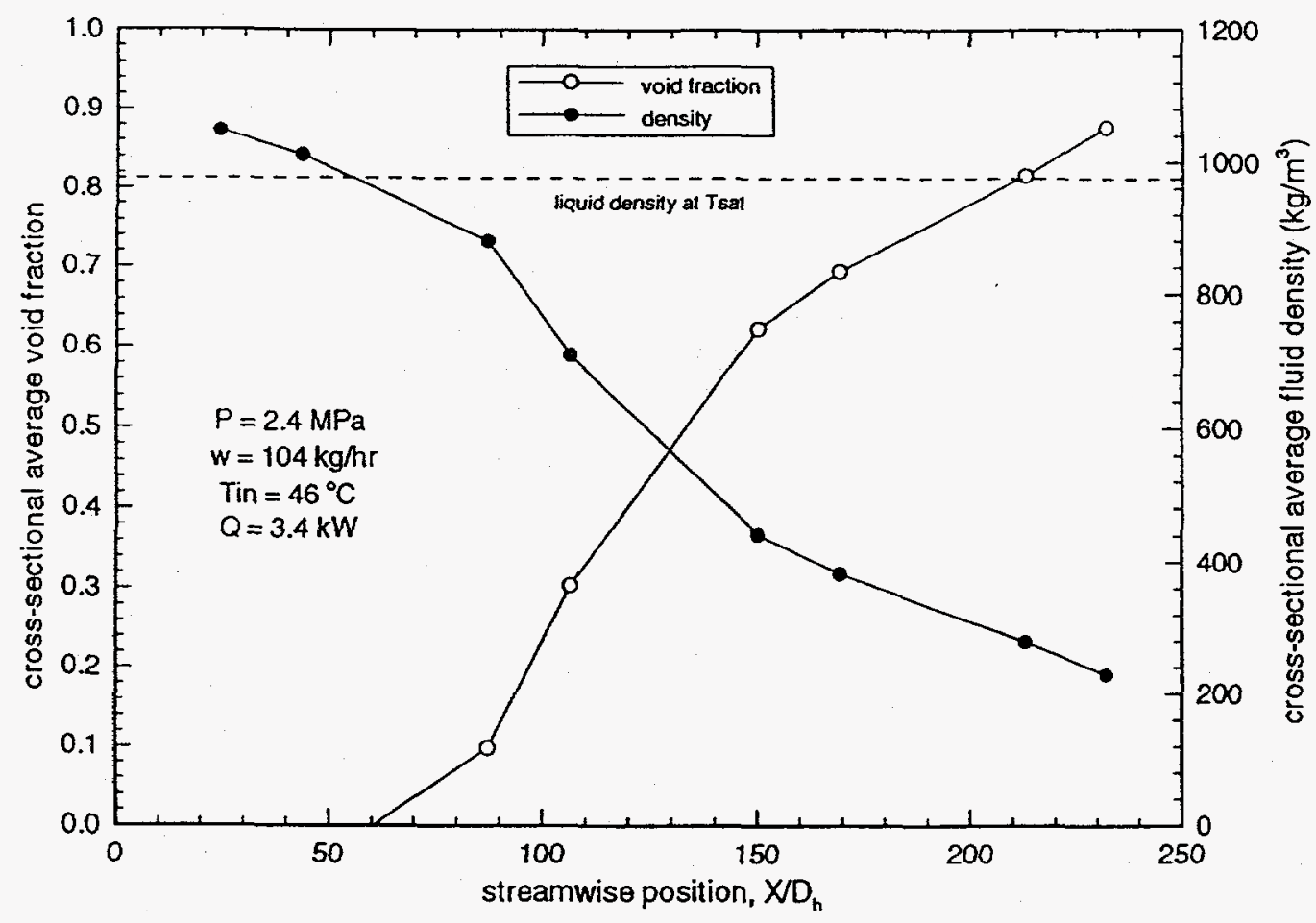

Figure 4 - X Dimension Void Fraction and Fluid Density Distributions Measured with GDS

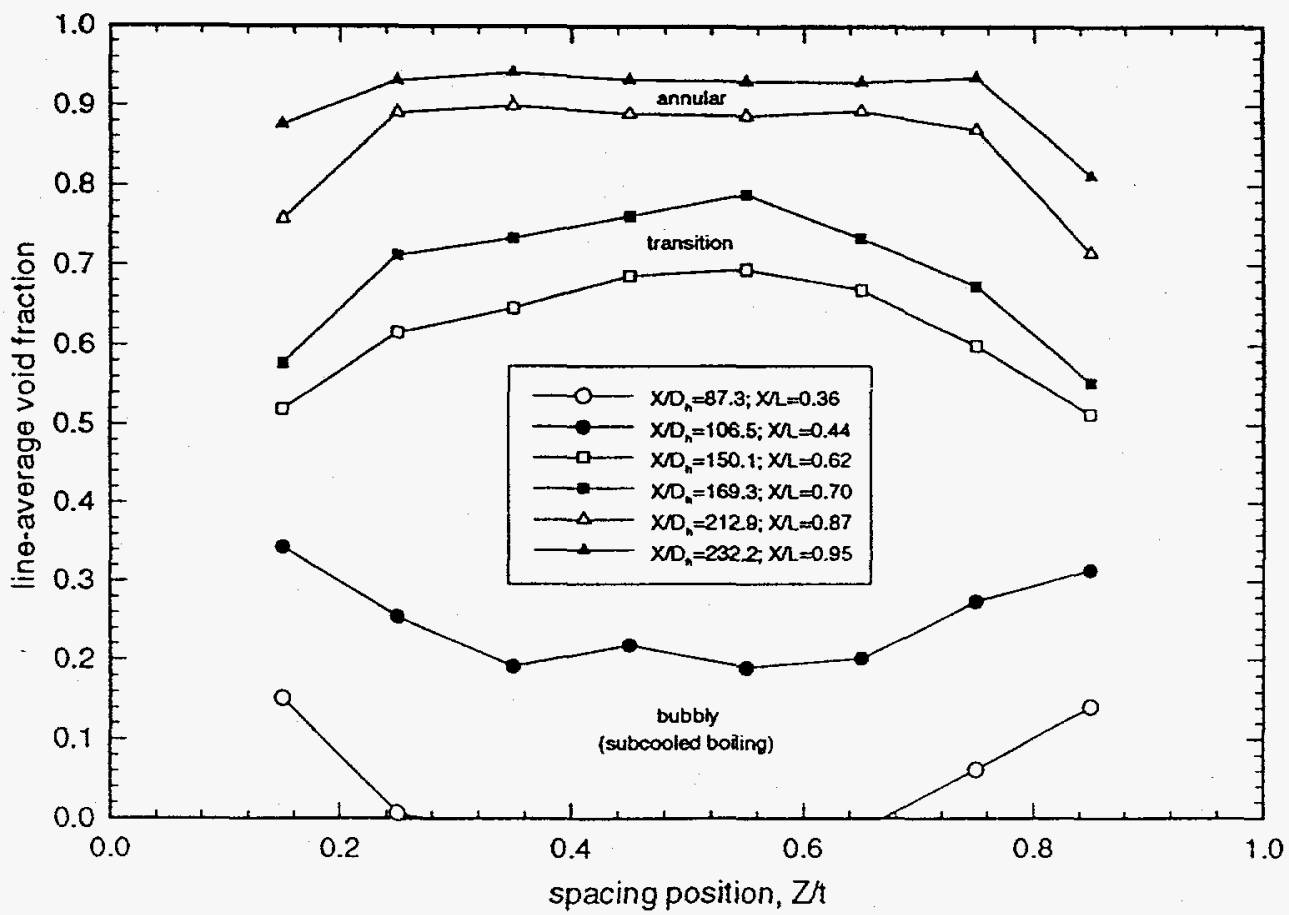

Figure 5 - Z Dimension Void Fraction Distributions in Various Flow Regimes (same conditions as Figure 4) 


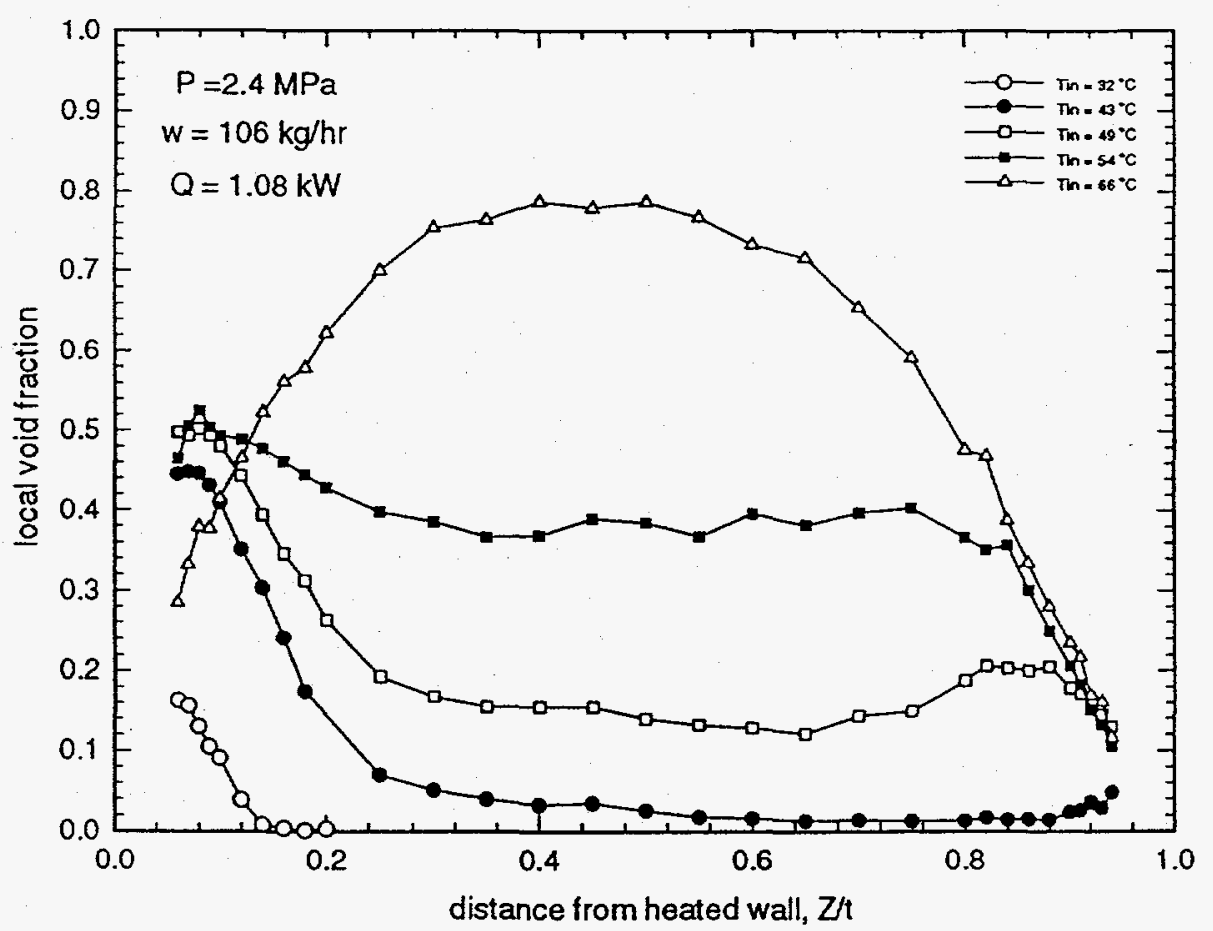

(a)

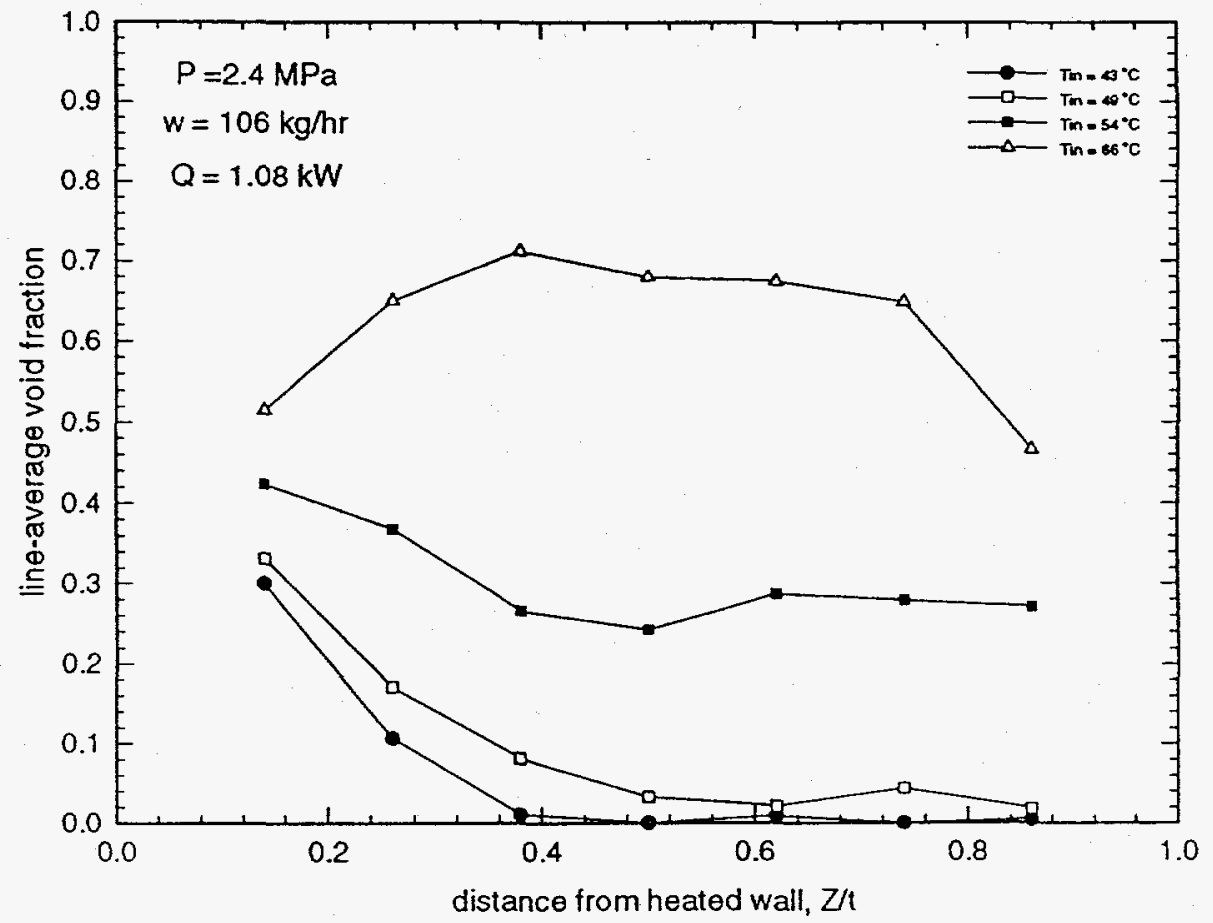

(b)

Figure 6 - Z Dimension Void Fraction Distributions in Subcooled Boiling Flow (a) Local Via HFA; (b) Line-Average Via GDS 


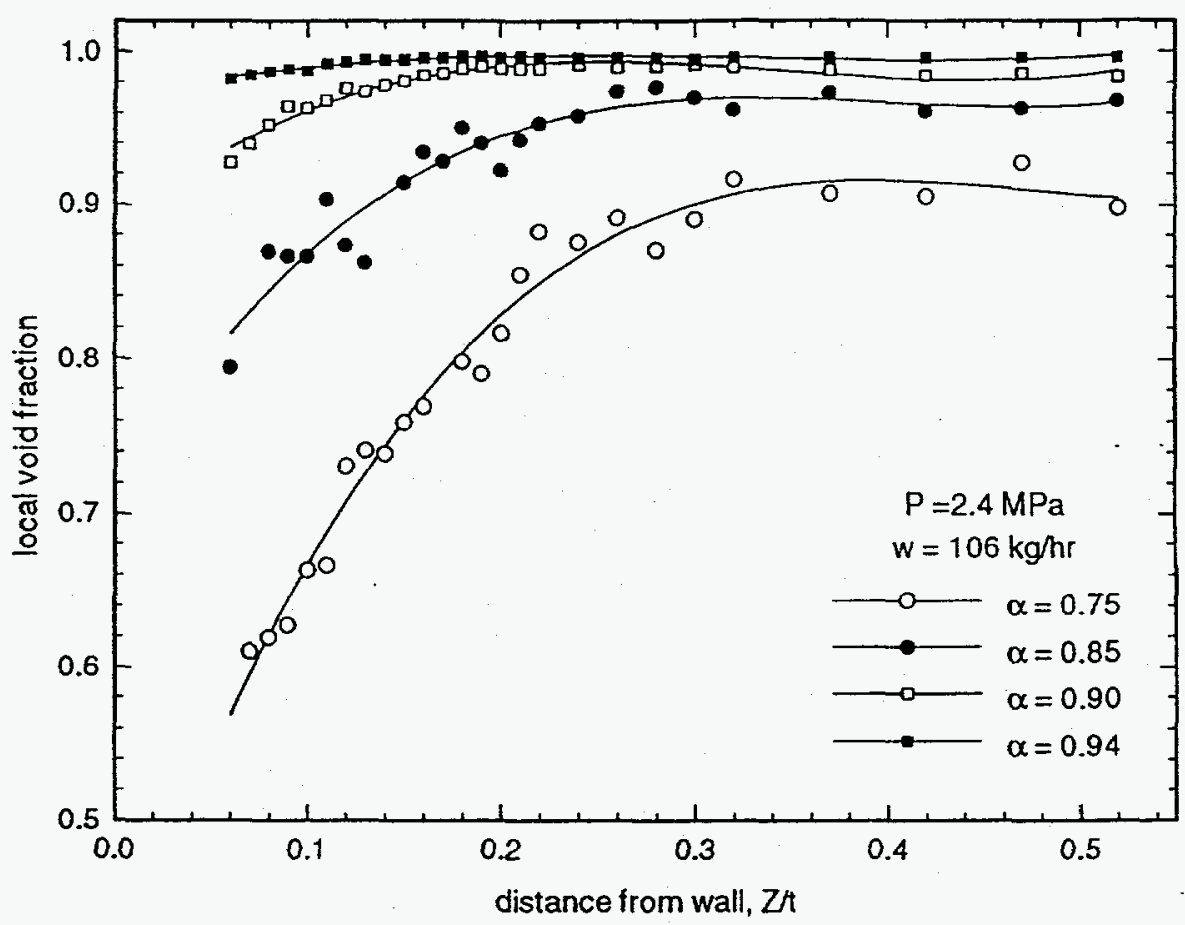

(a)

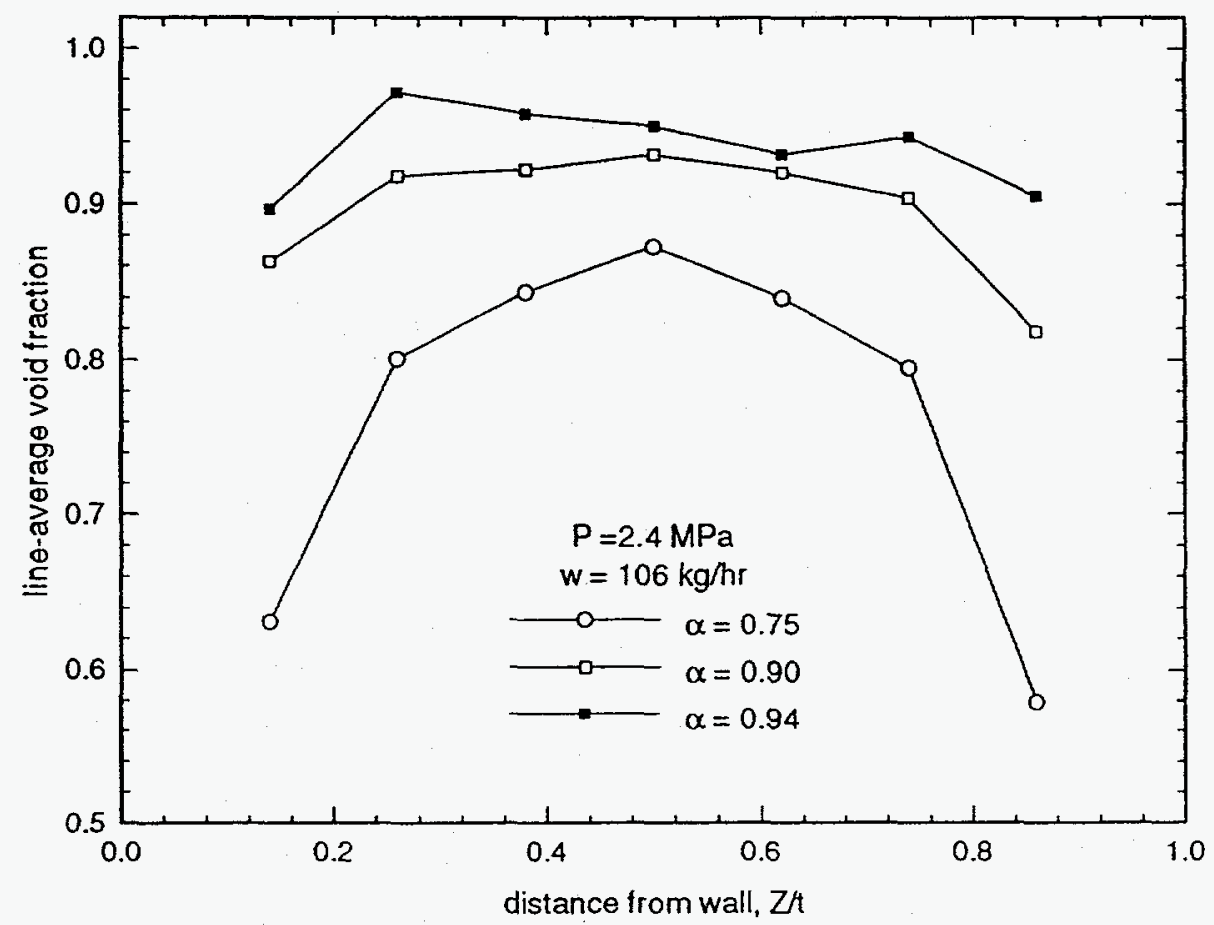

(b)

Figure 7 - Z Dimension Void Fraction Distributions in Adiabatic Annular Flow (a) Local Via HFA; (b) Line-Average Via GDS 

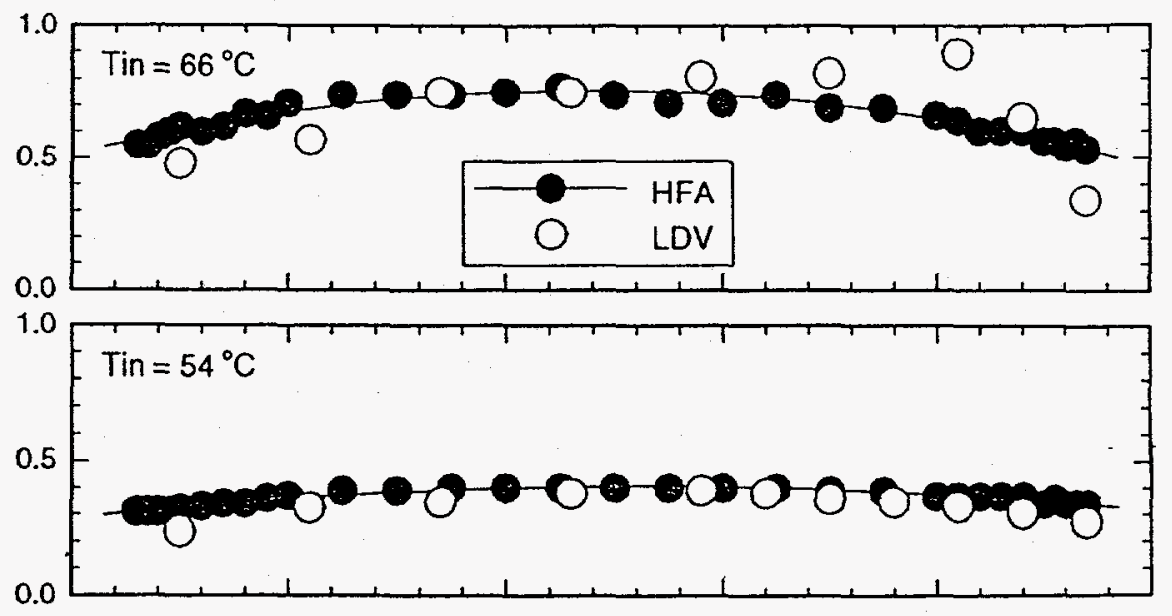

$P=2.4 \mathrm{MPa}$

$w=106 \mathrm{~kg} / \mathrm{hr}$

$Q=1.1 \mathrm{~kW}$

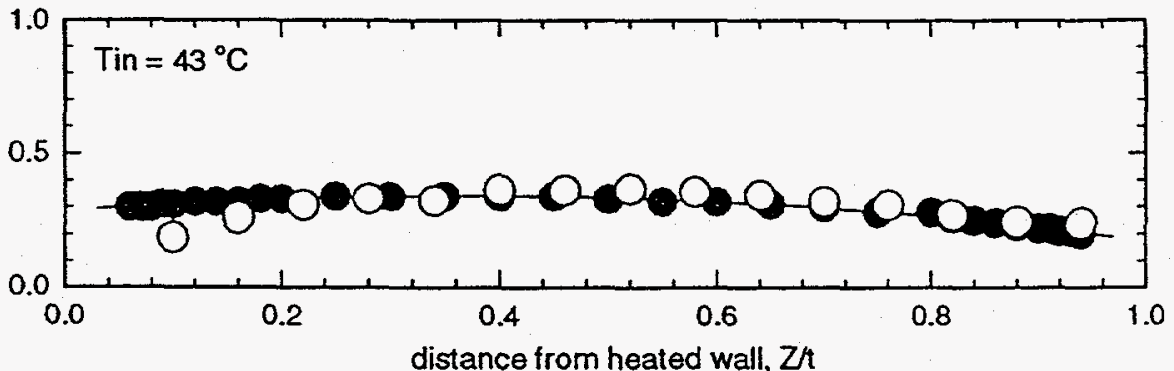

(a)
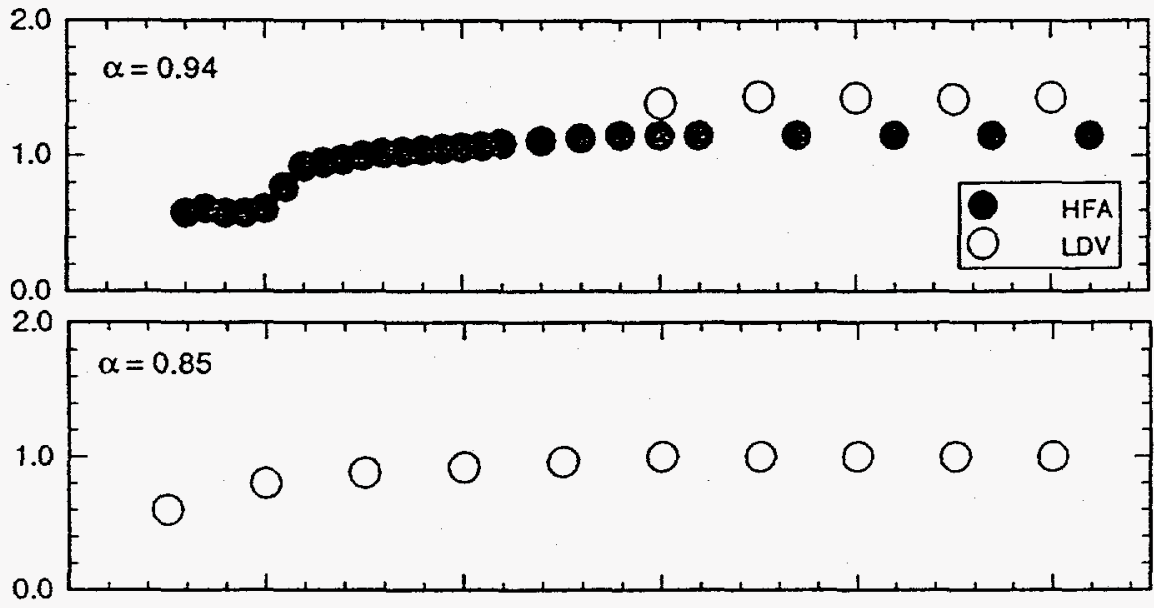

$P=2.4 \mathrm{MPa}$

$w=106 \mathrm{~kg} / \mathrm{hr}$

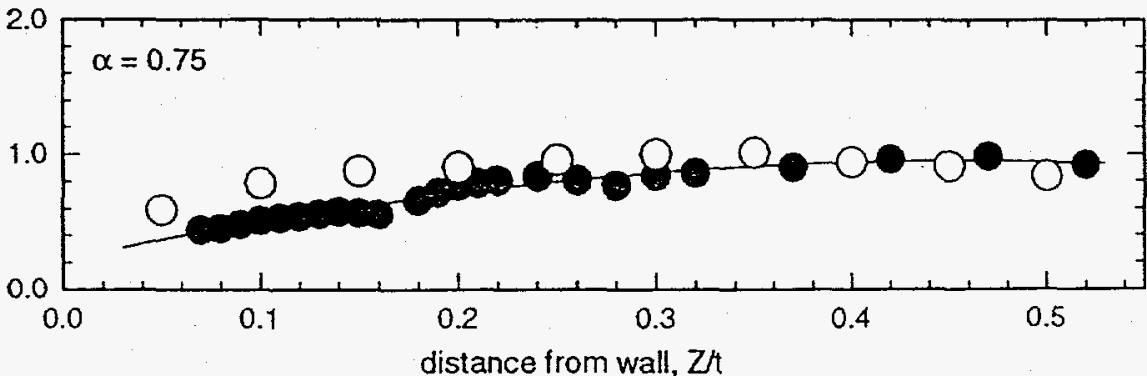

(b)

Figure 8 - Z Dimension Interfacial Velocity Distributions Via HFA and LDV

(a) Subcooled Boiling Flow; (b) Adiabatic Annular Flow 


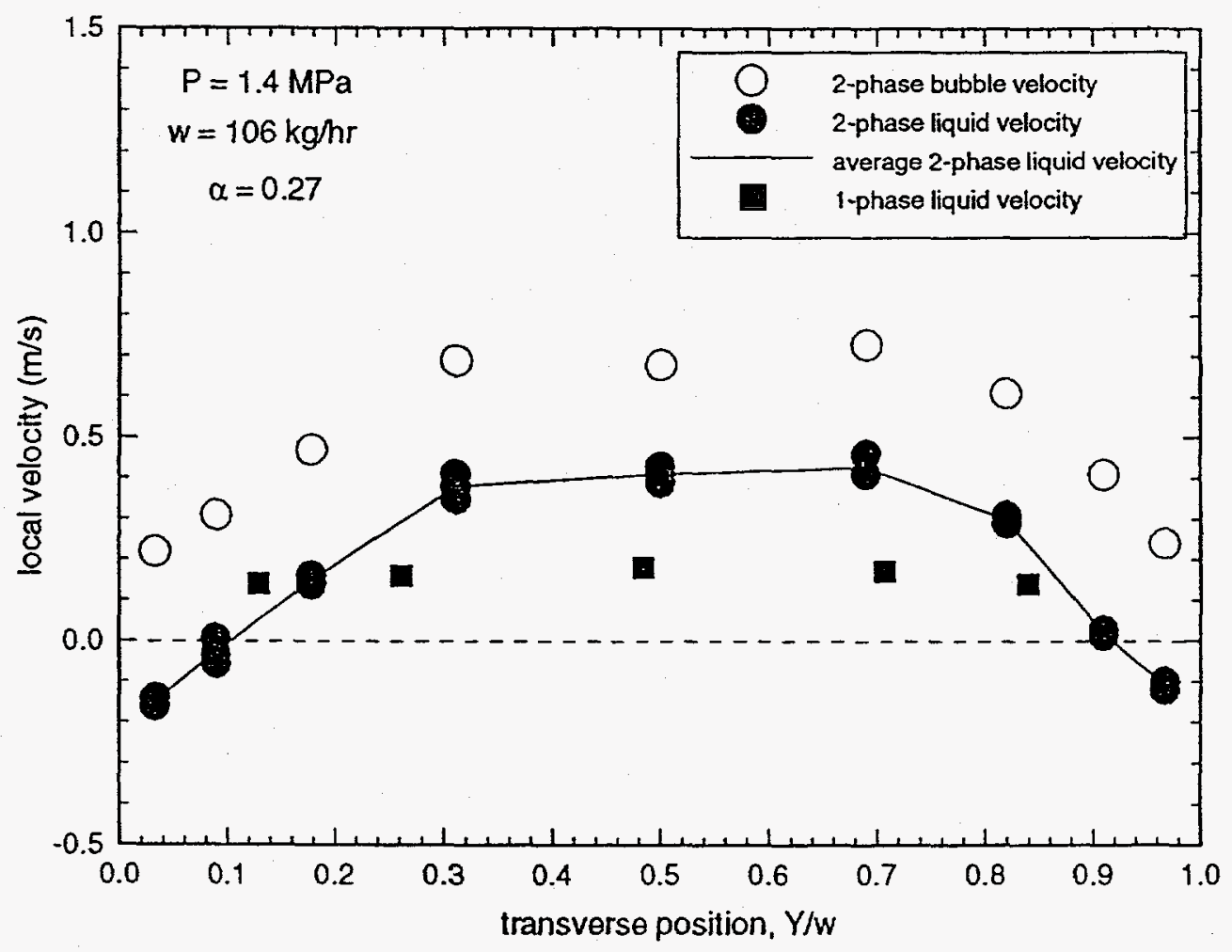

Figure 9 - Y Dimension LDV Velocity Scans 


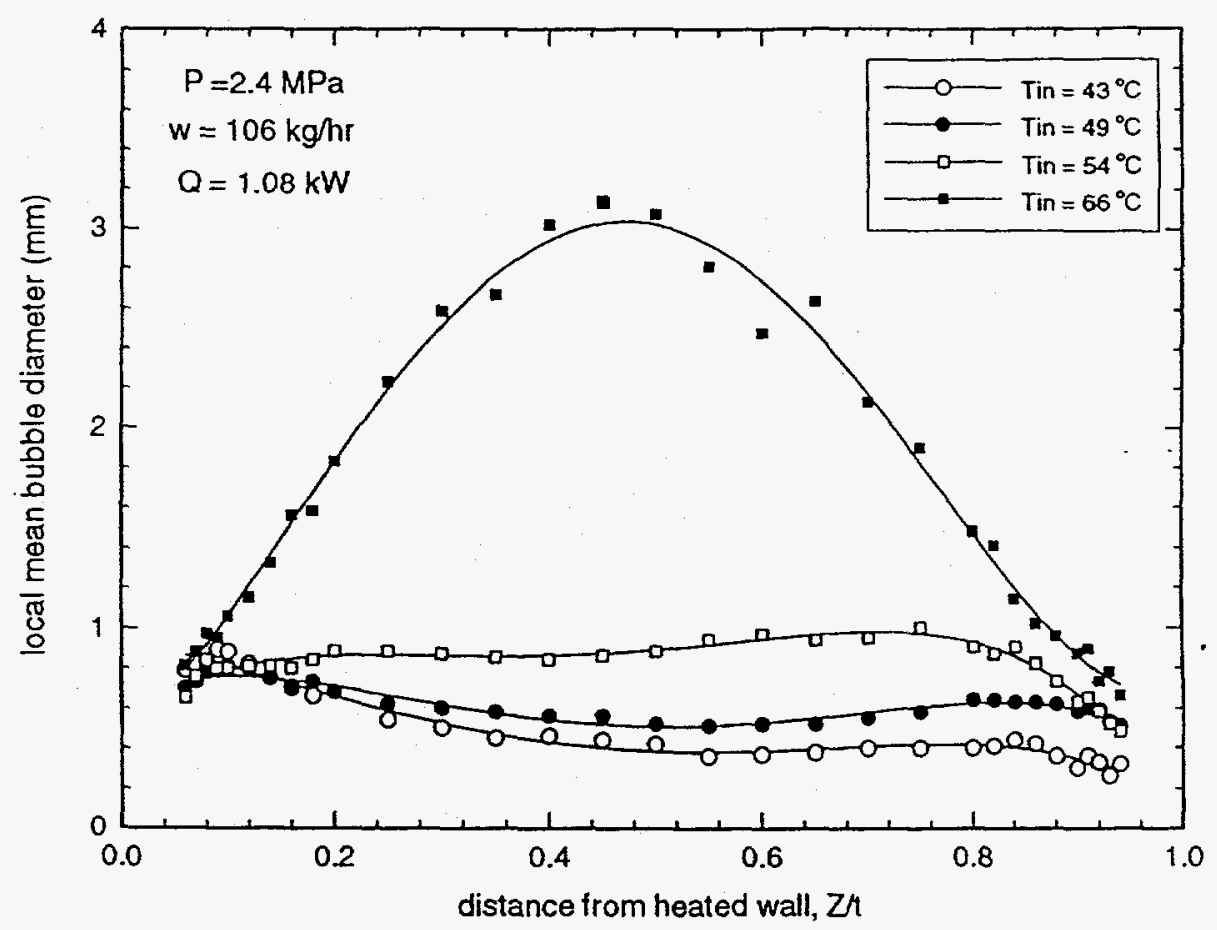

(a)

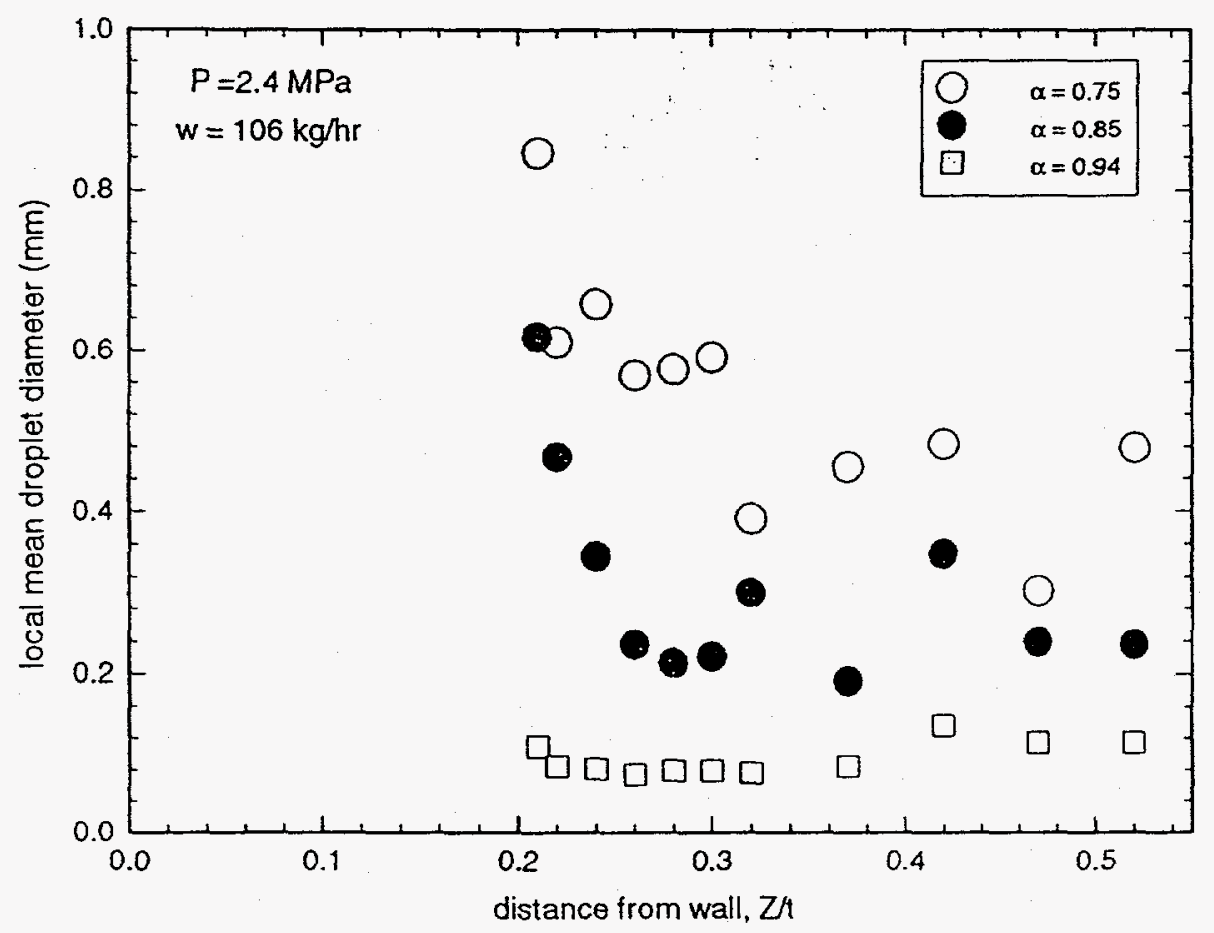

(b)

Figure 10 - Dispersed Field Mean Diameter Measured Via HFA (a) Bubbles in Subcooled Boiling Flow; (b) Droplets in Annular Flow 